\section{OPEN ACCESS}

Edited by:

Ling Zhang,

Jiangxi Agricultural University, China

Reviewed by:

Guofang Liu,

Chinese Academy of Sciences, China Xiaochi Ma,

University of California, Davis,

United States

*Correspondence:

Ika Djukic

ika.djukic@umweltbundesamt.at

Specialty section: This article was submitted to Forest Soils,

a section of the journal Frontiers in Forests and Global Change

Received: 09 March 2021 Accepted: 18 June 2021 Published: 14 July 2021

Citation:

Kwon T, Shibata $H_{\text {, }}$

Kepfer-Rojas S, Schmidt IK, Larsen KS, Beier C, Berg B,

Verheyen $K$, Lamarque J-F,

Hagedorn F, Eisenhauer N, Djukic I and TeaComposition Network (2021)

Effects of Climate and Atmospheric

Nitrogen Deposition on Early

to Mid-Term Stage Litter

Decomposition Across Biomes.

Front. For. Glob. Change 4:678480.

doi: 10.3389/ffgc.2021.678480

\title{
Effects of Climate and Atmospheric Nitrogen Deposition on Early to Mid-Term Stage Litter Decomposition Across Biomes
}

\section{TaeOh Kwon', Hideaki Shibata', Sebastian Kepfer-Rojas ${ }^{2}$, Inger K. Schmidt ${ }^{2}$, Klaus S. Larsen², Claus Beier2, Björn Berg'3 ${ }^{3}$ Kris Verheyen ${ }^{4}$, Jean-Francois Lamarque ${ }^{5}$, Frank Hagedorn ${ }^{6}$, Nico Eisenhauer ${ }^{7,8}$, Ika Djukic ${ }^{6 *}$ and TeaComposition Network}

${ }^{1}$ Field Science Center for Northern Biosphere, Hokkaido University, Sapporo, Japan, ${ }^{2}$ Department of Geosciences and Natural Resource Management, University of Copenhagen, Frederiksberg, Denmark, ${ }^{3}$ Department of Forest Sciences, University of Helsinki, Helsinki, Finland, ${ }^{4}$ Forest \& Nature Lab, Department of Forest and Water Management, Ghent University, Ghent, Belgium, ${ }^{5}$ National Center for Atmospheric Research, Boulder, CO, United States, ${ }^{6}$ Swiss Federal Institute for Forest, Snow and Landscape Research, Birmensdorf, Switzerland, ${ }^{7}$ German Centre for Integrative Biodiversity Research (iDiv) Halle-Jena-Leipzig, Leipzig, Germany, ${ }^{8}$ Institute of Biology, Leipzig University, Leipzig, Germany

Litter decomposition is a key process for carbon and nutrient cycling in terrestrial ecosystems and is mainly controlled by environmental conditions, substrate quantity and quality as well as microbial community abundance and composition. In particular, the effects of climate and atmospheric nitrogen $(\mathrm{N})$ deposition on litter decomposition and its temporal dynamics are of significant importance, since their effects might change over the course of the decomposition process. Within the TeaComposition initiative, we incubated Green and Rooibos teas at 524 sites across nine biomes. We assessed how macroclimate and atmospheric inorganic $\mathrm{N}$ deposition under current and predicted scenarios (RCP 2.6, RCP 8.5) might affect litter mass loss measured after 3 and 12 months. Our study shows that the early to mid-term mass loss at the global scale was affected predominantly by litter quality (explaining $73 \%$ and $62 \%$ of the total variance after 3 and 12 months, respectively) followed by climate and $\mathrm{N}$ deposition. The effects of climate were not litter-specific and became increasingly significant as decomposition progressed, with MAP explaining $2 \%$ and MAT $4 \%$ of the variation after 12 months of incubation. The effect of $\mathrm{N}$ deposition was litter-specific, and significant only for 12-month decomposition of Rooibos tea at the global scale. However, in the temperate biome where atmospheric $\mathrm{N}$ deposition rates are relatively high, the 12month mass loss of Green and Rooibos teas decreased significantly with increasing $\mathrm{N}$ deposition, explaining $9.5 \%$ and $1.1 \%$ of the variance, respectively. The expected changes in macroclimate and $\mathrm{N}$ deposition at the global scale by the end of this century are estimated to increase the 12-month mass loss of easily decomposable litter by 1.1$3.5 \%$ and of the more stable substrates by $3.8-10.6 \%$, relative to current mass loss. 
In contrast, expected changes in atmospheric $\mathrm{N}$ deposition will decrease the mid-term mass loss of high-quality litter by $1.4-2.2 \%$ and that of low-quality litter by $0.9-1.5 \%$ in the temperate biome. Our results suggest that projected increases in $\mathrm{N}$ deposition may have the capacity to dampen the climate-driven increases in litter decomposition depending on the biome and decomposition stage of substrate.

Keywords: tea bag, Green tea, Rooibos tea, litter decomposition, carbon turnover, nitrogen deposition, TeaComposition initiative

\section{INTRODUCTION}

Litter decomposition is a fundamental process in the carbon and nutrient cycling across all ecosystems (Chapin et al., 2011; Berg and McClaugherty, 2020). Decomposition rate is most closely related to litter quality (Cornwell et al., 2008; Djukic et al., 2018; Kotroczó et al., 2020), climate (Davidson and Janssens, 2006; Tóth et al., 2007; See et al., 2019), nutrient availability (Fog, 1988; Luo et al., 2018; Lilleskov et al., 2019; Juhos et al., 2021), and the abundance and diversity of soil organisms (Coûteaux et al., 1995; González and Seastedt, 2001; Pioli et al., 2020). The climate exerts a direct effect on decomposition by stimulation of decomposer activity through the increased temperature and precipitation (Zhang et al., 2008). However, the inhibitory influence of climate might occur when substrate moisture lies below $30 \%$ or above $80 \%$ and the mean annual temperature below $10^{\circ} \mathrm{C}$ (Prescott, 2010). The long-term climate conditions shape indirectly the prevailing vegetation and the quality of plant litter, which can have significant impacts on its turnover dynamics. Climate variables can explain up to $68 \%$ of the variability in litter decomposition rates on a global scale (Parton et al., 2007); thus changes in environmental conditions may have a significant impact on litter decomposition processes via both direct and indirect pathways. Carbon to nitrogen ratio and lignin content of the initial litter are considered to be good indicators of litter quality as they are related to nutrient availability and chemical properties of the studied substrate. For instance, litter with a high C:N ratio and lignin content decomposes more slowly (Makkonen et al., 2012) than litter with the inverse properties. Yet, the relative importance of diverse drivers may change over the course of the decomposition process. The early stage of litter decomposition (i.e., $0-30 \%$ mass loss) where most of the watersoluble compounds are released is especially sensitive to the environmental changes and the decomposition of holocellulose is promoted by higher nitrogen $(\mathrm{N})$ contents in initial litter and soil. In contrast, during the later stage of decomposition (>30\% mass loss), $\mathrm{N}$ exerts the opposite effect due to the suppressed oxidative enzymatic activities (Berg, 2014; Berg and McClaugherty, 2020). Although the central role of climate and litter quality in controlling litter decomposition rates is widely recognized, results on the effects of increased $\mathrm{N}$ input and climate on the decomposition in the field are inconsistent.

Depending on litter quality, responses to atmospheric $\mathrm{N}$ deposition may vary from positive for the decomposition of high-quality litter (high $\mathrm{N}$, low $\mathrm{C}: \mathrm{N}$ ratio) to negative for the decomposition of low-quality litter (high lignin, high C:N ratio; Fog, 1988; Zhou et al., 2017) through affecting the composition of the decomposer community. Similarly, several studies have shown that in $\mathrm{N}$-poor ecosystems, addition of $\mathrm{N}$ is likely to stimulate early-stage litter decomposition (Knorr et al., 2005), whereas in N-sufficient ecosystems inhibitory effects of $\mathrm{N}$ deposition have been reported through a reduced oxidative enzymatic activity (Hobbie, 2008; Hagedorn et al., 2012; Norris et al., 2013). A meta-analysis revealed an inhibitory effect of ambient $\mathrm{N}$ deposition between 5 and $10 \mathrm{~kg} \mathrm{~N}^{-1}$ year $^{-1}$ on litter decomposition for a period of 1-72 months (Knorr et al., 2005). Although much is known about the regulatory factors of litter decomposition, the results on the effects of increased $\mathrm{N}$ deposition on litter decomposition remain inconsistent (Pei et al., 2020; Hood-Nowotny et al., 2021). Hence, the importance of regulatory factors might be strongly context-dependent and may differ among ecosystems and litter types (Bradford et al., 2016).

Increases of the global mean annual surface temperature $\left(1.0-3.7^{\circ} \mathrm{C}\right)$ and mean annual precipitation $(28.8-65.0 \mathrm{~mm})$ are projected for the end of this century (IPCC, 2014; Thorpe and Andrews, 2014). The atmospheric total inorganic $\mathrm{N}$ deposition rate on land and transitional area is expected to increase by $1.2 \mathrm{~kg}$ $\mathrm{N} \mathrm{ha}^{-1}$ year $^{-1}$ (RCP 2.6) to $1.9 \mathrm{~kg} \mathrm{~N} \mathrm{ha}^{-1}$ year $^{-1}$ (RCP 8.5) by the end of this century (Lamarque et al., 2013). Since $\mathrm{N}$ and $\mathrm{C}$ cycles are tightly coupled, an increase of $\mathrm{N}$ in soil through increased atmospheric $\mathrm{N}$ deposition may alter the humification of litter and thus soil C sequestration (Janssens et al., 2010; Prescott, 2010; Berg and McClaugherty, 2020). In addition, not only climate-driven shifts in vegetation composition (Rizzetto et al., 2016; Boutin et al., 2017), but also $\mathrm{N}$ driven changes in plant diversity (Bobbink et al., 2010) might not only influence the microclimate but also litter quality, which significantly affects decomposition patterns (Gaudio et al., 2015) and thus might have profound implications for the global $\mathrm{C}$ storage and consequently climate change. Therefore, it is crucial to explore potential effects of changes in climate and $\mathrm{N}$ deposition on litter decomposition.

To understand the effects of variation in climate, $\mathrm{N}$ deposition, and other environmental factors on litter decomposition at the global scale, standardization in experimental materials and methodology is mandatory. The TeaComposition initiative has collected harmonized data on litter mass loss over time using standardized litter (i.e., commercially available tea bags; Djukic et al., 2018). Using this approach, we evaluated the effects of macroclimate and $\mathrm{N}$ deposition on the global litter mass loss of fast-decomposing Green tea and slow-decomposing Rooibos tea after 3 and 12 months of in situ incubation. For future predictions, two different $\mathrm{N}$ deposition and climate scenarios were used. The number and distribution of field 


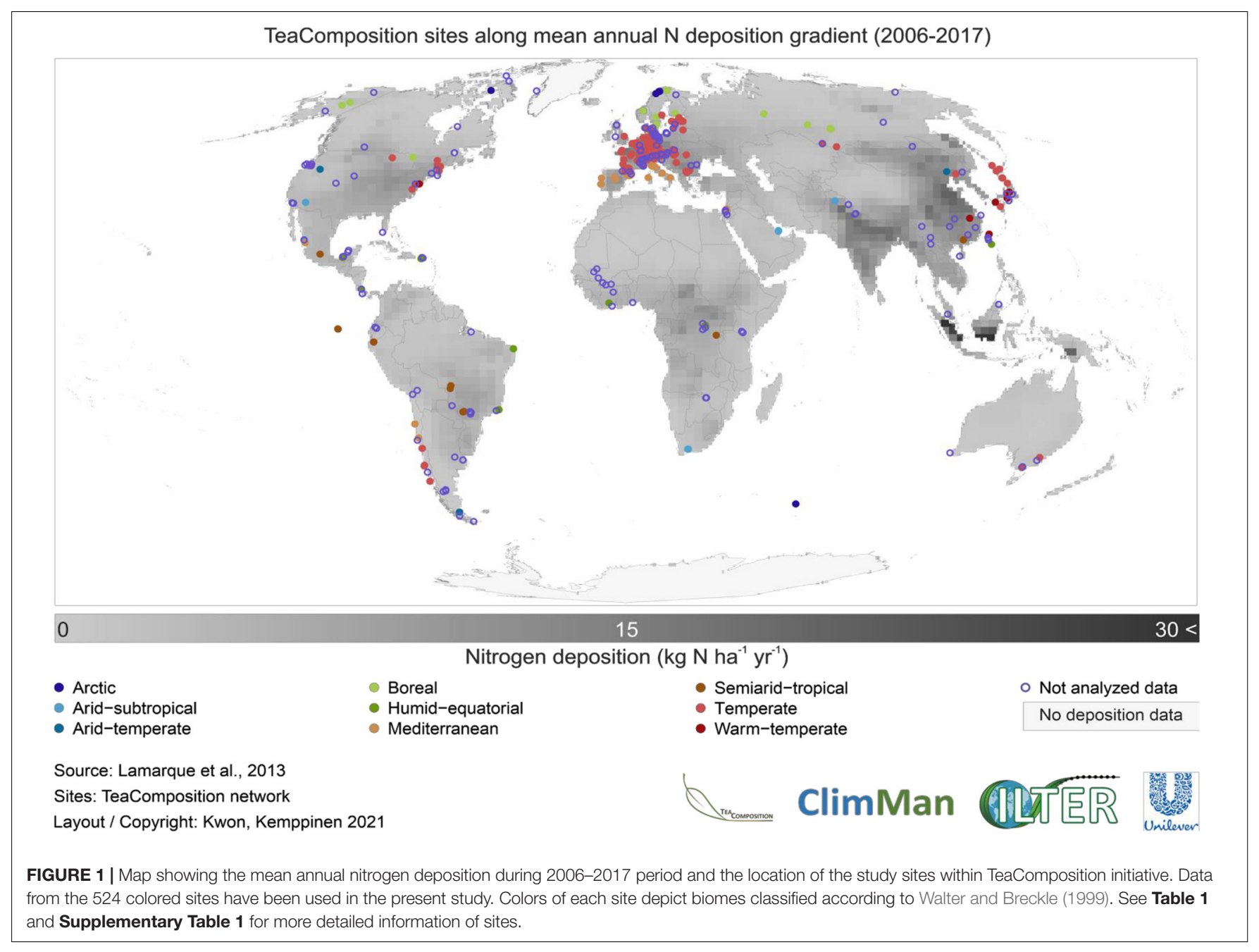

sampling locations often limit our understanding of ecological processes. Therefore, in our analyses we shed more light on the decomposition process in the temperate biome due to the greatest data availability and the largest range of $\mathrm{N}$ deposition.

The aims of this study are to determine (1) the relationship between macroclimatic factors, $\mathrm{N}$ deposition, and litter quality on mass loss of Green and Rooibos teas across biomes, (2) whether the observed relationships at the global scale hold true for regional scale (i.e., temperate biome where $\mathrm{N}$ deposition is highest), and (3) the relationship between predicted changes in macroclimate, $\mathrm{N}$ deposition, and first year leaf litter mass loss at global and regional scales. Specifically, we hypothesize (1) that the control of early to mid-stage decomposition will be driven by litter quality $>$ climate $>\mathrm{N}$ deposition on the global scale; (2) that the inhibitory effect of $\mathrm{N}$ deposition on the progressed stage of decomposition will be more pronounced at the regional scale with higher $\mathrm{N}$ deposition rates than at the global scale; (3) that a potential climate change-induced increase of litter decomposition might be mitigated through a potential negative feedback of $\mathrm{N}$ deposition on the progressed stage of decomposition.

\section{MATERIALS AND METHODS}

\section{Study Sites}

We used data gained by the global TeaComposition initiative ${ }^{1}$ coming from untreated control plots. Data from 394 sites $(5,581$ teabags) after 3 -month incubation and 423 sites (4,583 teabags) after 12-month incubation are collected across nine biomes (Figure 1, Table 1, and Supplementary Table 1). Each site was assigned to one of nine terrestrial biomes, defined by Walter and Breckle (1999). Sub-sites with different elevations, locations, and vegetation types were considered as separate sites. For 3month incubation, we used the mean monthly precipitation (MMP), mean monthly air temperature (MMAT), and the mean monthly $\mathrm{N}$ deposition (MMN) based on the real incubation period, while for 12-month incubation, mean annual average values of these variables were used. Climate data were extracted from the CHELSA version 1.2 (Climatologies at High resolution for the Earth's Land Surface Areas²; Karger et al., 2017). The atmospheric $\mathrm{N}$ deposition at each site was resampled by bilinear

\footnotetext{
${ }^{1}$ https://www.teacomposition.org/

${ }^{2}$ https://chelsa-climate.org/
} 
TABLE 1 | Summarized characteristics of the study sites used for the analyses within the TeaComposition initiative.

\begin{tabular}{|c|c|c|c|c|c|c|c|c|}
\hline \multirow[b]{2}{*}{ Biomes } & \multicolumn{4}{|c|}{ Ca. 3-month incubation } & \multicolumn{4}{|c|}{ Ca. 12-month incubation } \\
\hline & $\begin{array}{c}\text { Number }{ }^{A} \text { of } \\
\text { sites } \\
\text { (teabags) }\end{array}$ & $\begin{array}{l}\text { Climate } \\
(\mathrm{MMP})^{\mathrm{B}}\end{array}$ & $\begin{array}{l}\text { Climate } \\
(\mathrm{MMT})^{\mathrm{C}}\end{array}$ & $\begin{array}{l}\text { N deposition } \\
(\mathrm{MMN})^{\mathrm{D}}\end{array}$ & $\begin{array}{c}\text { Number of } \\
\text { sites } \\
\text { (teabags) }\end{array}$ & $\begin{array}{l}\text { Climate } \\
(\mathrm{MAP})^{\mathrm{E}}\end{array}$ & $\begin{array}{l}\text { Climate } \\
\text { (MAT) }^{F}\end{array}$ & $\begin{array}{l}\text { N deposition } \\
\text { (MAN) }^{G}\end{array}$ \\
\hline Arctic & $3(124)$ & $59(2)^{b c}$ & $8(1)^{c}$ & $0.07(0.03)^{b}$ & $80(419)$ & $487(6)^{\mathrm{C}}$ & $-2(0)^{e}$ & $1.14(0.04)^{d}$ \\
\hline Boreal & $21(475)$ & $63(3)^{b c}$ & $13(0)^{\mathrm{C}}$ & $0.25(0.03)^{b}$ & $22(652)$ & $513(36)^{\mathrm{C}}$ & $1(1)^{d}$ & $2.84(0.32)^{b c}$ \\
\hline Temperate & 284 (3927) & $80(2)^{b}$ & $15(0)^{\mathrm{C}}$ & $1.00(0.02)^{a}$ & 231 (2572) & $862(21)^{\mathrm{b}}$ & $7(0)^{\mathrm{c}}$ & $10.57(0.31)^{\mathrm{a}}$ \\
\hline $\begin{array}{l}\text { Warm- } \\
\text { temperate }\end{array}$ & $6(120)$ & $182(41)^{\mathrm{a}}$ & $23(1)^{\mathrm{ab}}$ & $0.61(0.09)^{a b}$ & $5(105)$ & $2451(361)^{\mathrm{a}}$ & $16(1)^{a b}$ & $7.41(1.31)^{\mathrm{ab}}$ \\
\hline Arid-temperate & $3(53)$ & $32(14)^{C}$ & $16(2)^{b c}$ & $0.50(0.38)^{b}$ & $2(58)$ & $275(22)$ & $9(2)$ & $1.81(0.70)$ \\
\hline Mediterranean & $40(428)$ & $39(5)^{c}$ & $18(1)^{b}$ & $0.48(0.05)^{b}$ & $44(501)$ & $755(51)^{\mathrm{b}}$ & $13(1)^{b}$ & $5.31(0.53)^{b}$ \\
\hline Arid-subtropical & $9(141)$ & $23(11)^{\mathrm{C}}$ & $26(1)^{a}$ & $0.14(0.04)^{b}$ & $6(40)$ & $340(98)^{c}$ & $23(0)^{\mathrm{a}}$ & $1.73(0.78)^{\mathrm{cd}}$ \\
\hline $\begin{array}{l}\text { Humid- } \\
\text { equatorial }\end{array}$ & $14(104)$ & $139(14)^{\mathrm{a}}$ & $26(0)^{\mathrm{a}}$ & $0.24(0.03)^{b}$ & $21(142)$ & $1685(148)^{\mathrm{a}}$ & $24(0)^{a}$ & $2.21(0.34)^{\mathrm{cd}}$ \\
\hline $\begin{array}{l}\text { Semiarid- } \\
\text { tropical }\end{array}$ & $14(209)$ & $159(11)^{\mathrm{a}}$ & $21(2)^{a b}$ & $0.48(0.07)^{b}$ & $12(94)$ & $1183(45)^{\mathrm{a}}$ & $19(2)^{\mathrm{a}}$ & $4.48(0.83)^{\mathrm{bc}}$ \\
\hline Mean & & $89(11)$ & $18(1)$ & $0.42(0.08)^{b}$ & & $951(88)$ & $12(1)$ & $4.17(0.57)$ \\
\hline
\end{tabular}

Mean (SE) of climates and $N$ deposition at each biome.

Detailed table on the single site characteristics can be found in the Supplementary Material.

ANumber of sites (teabags) is for sites (teabags) used for both the teas, Green tea and Rooibos tea at each incubated period.

${ }^{\mathrm{B}} \mathrm{MMP}\left(\mathrm{mm}\right.$ month $\left.^{-1}\right)=$ Mean monthly precipitation during real incubation period at each site.

${ }^{\mathrm{C}} \mathrm{MMT}\left({ }^{\circ} \mathrm{C}\right)=$ Mean monthly temperature during real incubation period at each site.

${ }^{D} M M N\left(\mathrm{~kg} \mathrm{~N} \mathrm{ha}^{-1} \mathrm{month}^{-1}\right)=$ Mean monthly N deposition during real incubation period at each site.

${ }_{\mathrm{E}} \mathrm{MAP}\left(\mathrm{mm}_{\mathrm{m}}\right.$ year $\left.^{-1}\right)=$ Mean annual precipitation.

${ }^{F_{M A T}}\left({ }^{\circ} \mathrm{C}\right)=$ Mean annual temperature.

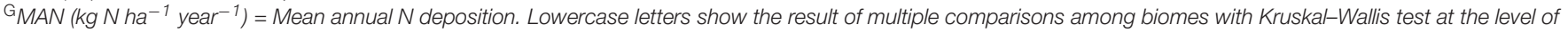
$P<0.05$.

interpolation on a rectilinear 2D grid of Atmospheric Chemistry and Climate Model Intercomparison Project (ACCMIP) dataset with a spatial resolution of 1.9 (latitude) $\times 2.5$ (longitude) degree (Lamarque et al., 2013). The ACCMIP dataset is composed of historical deposition covering the period from 1850 to 2000 and the projected deposition with RCP scenarios until 2100 (Van Vuuren et al., 2011; Lamarque et al., 2013). The data on N depositions are based on the RCP 2.6 scenario from 2007 to 2016 for each site. The mean annual air temperature (MAAT) in our dataset ranges from $-2^{\circ} \mathrm{C}$ to $24^{\circ} \mathrm{C}$ on the global scale and is $7^{\circ} \mathrm{C}$ in the temperate biome. The mean annual precipitation (MAP) ranges from $275 \mathrm{~mm}$ to $2451 \mathrm{~mm}$ at the global scale and is around $862 \mathrm{~mm}$ in the temperate biome. The estimated mean annual total inorganic $\mathrm{N}$ deposition (MAN) ranges from 1 to $11 \mathrm{~kg} \mathrm{~N} \mathrm{ha}^{-1}$ year ${ }^{-1}\left(0.2-22.0 \mathrm{~kg} \mathrm{~N} \mathrm{ha}^{-1}\right.$ year $^{-1}$ with a whole range) on the global scale and is around $11 \mathrm{~kg} \mathrm{~N} \mathrm{ha}^{-1}$ year $^{-1}(0.7-22.0 \mathrm{~kg} \mathrm{~N}$ $\mathrm{ha}^{-1}$ year $^{-1}$ with a whole range) in the temperate biome (Table 1; site specific data can be found in the Supplementary Table 1).

\section{Litter Bag Study}

Within the TeaComposition initiative (Djukic et al., 2018), commercially available tea bags of Green tea ( $\mathrm{C} / \mathrm{N}$ ratio of 12.3$)$ and Rooibos tea (C/N ratio of 42.9; Keuskamp et al., 2013) were incubated ( $n=4$ per litter type and sampling period) in the field over a period of 3 and 12 months. The tea was contained in woven nylon bags with $0.25 \mathrm{~mm}$ mesh size allowing access only for microorganisms and fine roots. Tea bags were buried in the upper $5 \mathrm{~cm}$ of the top-soil in the summer of 2016 in both the northern and southern hemispheres (i.e., start in summer; June-August in northern hemisphere and December-February in southern hemisphere). After incubation, bags were excavated and carefully cleaned of soil and roots, dried at $70^{\circ} \mathrm{C}$ for $48 \mathrm{~h}$, and weighed. The remaining mass after the incubation was linearly normalized to 3 and 12 months on dry weight and expressed in percentage (\%) of the initial litter weight. When remaining litter was visibly contaminated, remaining mass of litter was estimated by subtracting ash weight (representing mineral portion) obtained after heating the sample in a muffle oven at $500^{\circ} \mathrm{C}$ for $16 \mathrm{~h}$ from remaining mass of visibly contaminated litter.

\section{Data Analyses \\ Effects of Climate and N Deposition on Mass Loss Between Tea Types and Incubation Time}

We linearly normalized all mass loss data to a fixed period because not all tea bags were incubated for exactly 3 ( $91 \pm 8$ days; overall mean \pm standard deviation; number of sites $=394)$ and 12 months ( $369 \pm 9$ days; number of sites $=423$ ).

To determine the significant differences of the means of mass loss at site level of each tea type across biomes after 3-month and 12-month incubation, the Kruskal-Wallis test was performed. This non-parametric test was used because preliminary analysis indicated at least one of the assumptions of normality and homogeneity of variance was not met. When the result of the Kruskal-Wallis test showed a significant difference across biomes, a non-parametric post hoc test was conducted using the "kruskal" function in the package "agricolae" in R Statistical 
Software with the Holm-adjusted $p$-value, set to $p<0.05$ for statistical significance, for multiplicity correction (Holm, 1979; De Mendiburu, 2017).

To investigate the effects of climatic variables and $\mathrm{N}$ deposition on mass loss after 3 and 12 months for both teas or each tea type separately, we applied linear mixed-effects models (Bates et al., 2015) with tea type for both teas, climate, and $\mathrm{N}$ deposition as fixed factors and site as random factor. For 3-month incubation, the mean monthly values of climate and $\mathrm{N}$ deposition were calculated and used with real incubation period at each site. For 12-month incubation, the mean annual data of climate and $\mathrm{N}$ deposition were used. The final model was selected with backward selection by deleting non-significant terms. While determining the final model, we also examined the possibility of multicollinearity between fixed factors using a variance inflation factor (VIF), with an acceptable VIF score $<3$ (Kock and Lynn, 2012). The same procedure has been applied separately for data from temperate biome, due to the greatest data availability and the largest range of $\mathrm{N}$ deposition at the regional scale.

\section{Projection of Future Litter Decomposition}

We used the RCP 2.6 and RCP 8.5 IPCC scenarios to analyze the relationships between the change of mass loss and the change of climate and $\mathrm{N}$ deposition by the end of this century (Van Vuuren et al., 2011; Lamarque et al., 2013; IPCC, 2014; Table 2). Projected data on MAT and MAP by the end of this century were obtained from IPCC (2014) and the Coupled Model Intercomparison Project 5 (CMIP5; Thorpe and Andrews, 2014), respectively. For the change of atmospheric $\mathrm{N}$ deposition, we used the simulated dataset with RCP scenarios from ACCMIP aforementioned, supplied by National Center for Atmospheric Research in United States (Lamarque et al., 2013). According to these simulations, the surface temperature is expected to increase between 1 and $3.7^{\circ} \mathrm{C}$ between 2081 and 2100 relative to the period of 1986-2005, while precipitation is predicted to increase by 28.8 to $65.0 \mathrm{~mm} \mathrm{year}^{-1}$ between 2079 and 2098 in comparison to 1986-2005. In addition, $\mathrm{N}$ deposition is expected to increase by 1.2 to $1.9 \mathrm{~kg} \mathrm{~N} \mathrm{ha}^{-1}$ year $^{-1}$ by $2090-2099$ relative to the period of 2000-2009 (Table 2). We calculated the percent changes in mass loss of Green and Rooibos teas, relative to mass loss measured after current 1-year decomposition, by the end of the 21 st century by using data on predicted changes in MAT, MAP, and MAN as well as the results of linear mixed-effects models between those factors and mass loss of tea types.

\section{Software Used for Data Processing and Statistical Analysis}

All the geographical analyses on climate, $\mathrm{N}$ deposition data, and site locations were processed using QGIS (Quantum GIS Development Team, 2017, version 2.18.14). All statistical analyses were carried out with $\mathrm{R}$ ( $\mathrm{R}$ Core Team, 2019, version 3.4.4). To quantify the explained percentage of variance by fixed factors in a linear mixed-effects model using the "lmer" function in the "lme4" package in $\mathrm{R}$, we used the "variancePartition" package in R (Hoffman and Schadt, 2016). Overall, model quality was further quantified by calculating marginal $R^{2}$ (fixed
TABLE 2 | Change in mean annual temperature $\left(\triangle M A T,{ }^{\circ} \mathrm{C}\right)$, mean annual precipitation ( $\triangle \mathrm{MAP}, \mathrm{mm}$ year ${ }^{-1}$ ), and mean annual $\mathrm{N}$ deposition ( $\Delta \mathrm{N}$ deposition, $\mathrm{kg} \mathrm{N} \mathrm{ha}^{-1}$ year $^{-1}$ ) by the late 21 st century for two RCP scenarios as compared to the period 1986-2005 for $\triangle \mathrm{MAT}$ and $\triangle \mathrm{MAP}$ and to the period 2000-2009 for $\Delta \mathrm{N}$ deposition.

\begin{tabular}{lccc}
\hline Scenario & $\mathbf{2 0 8 1 - 2 1 0 0}$ & $\mathbf{2 0 7 9 - 2 0 9 8}$ & $\mathbf{2 0 9 0 - 2 0 9 9}$ \\
\cline { 2 - 4 } & $\boldsymbol{\Delta}$ MAT (likely range) & $\mathbf{\Delta M A P}(\mathrm{SE})$ & $\boldsymbol{\Delta} \mathbf{N}$ deposition \\
\hline RCP 2.6 & $1.0(0.3-1.7)$ & $28.8(2.9)$ & 1.2 \\
RCP 8.5 & $3.7(2.6-4.8)$ & $65.0(4.4)$ & 1.9 \\
\hline
\end{tabular}

SE means standard error.

effects only) and conditional $R^{2}$ (fixed plus random effects) with "r.squaredGLMM" function in the "MuMIn" package in $\mathrm{R}$ (Nakagawa and Schielzeth, 2013).

\section{RESULTS}

\section{Effect of Climate and N Deposition on Mass Loss Across All Biomes}

Across all biomes Green tea lost 2.4 times more mass $[58.9 \pm 6.5 \%$, Mean of mass loss \pm Standard error (SE)] than Rooibos tea $(24.3 \pm 2.8 \%)$ during the 3 -month decomposition period and 1.9 times more mass $(66.4 \pm 2.4 \%)$ than Rooibos tea $(34.9 \pm 3.2 \%)$ during the 12 -month decomposition period (Figure 2). The lowest mass loss after 3 and 12 months of incubation for both tea types was observed under the aridtemperate climate, while the highest mass loss was under the warm-temperate and semiarid-tropical biomes (after 3 months of incubation) and warm-temperate and humid-equatorial biomes (after 12 months of incubation; Figure 2).

The 3-month mass loss of both tea types correlated positively with precipitation and temperature (Table 3). Tea type explained $72.5 \%$, precipitation $1.6 \%$, and temperature $0.2 \%$ of the variance of mass loss. When the analysis was run for each tea type separately, precipitation was positively correlated with mass loss for both Green tea (4.2\% of variance) and Rooibos tea (9.2\% of variance). In addition, temperature was positively correlated with mass loss of Green tea ( $0.9 \%$ of variance) and Rooibos tea $(0.6 \%$ of variance; Table 3 and Figure 3 ).

Similarly, the 12-month mass loss of both tea types was also strongly affected by tea type (explaining $61.8 \%$ of the variance) but less affected by tea types than 3-month incubation. As well, precipitation $(2.3 \%)$, temperature $(4.4 \%)$, and $\mathrm{N}$ deposition $(0.3 \%$ of variance) were positively correlated with mass loss (Table 3 ). For Green tea, precipitation (8.2\% of variance) and temperature (11.7\% of variance) were in positive relationships with mass loss. And for Rooibos tea, precipitation (5.9\% of variance), temperature (14.9\% of variance), and $\mathrm{N}$ deposition $(2.0 \%$ of variance) were positively correlated with mass loss.

\section{Decomposition in the Temperate Biome}

When only data for the temperate biome were analyzed, 3month mass loss of both tea types was also positively related 
A

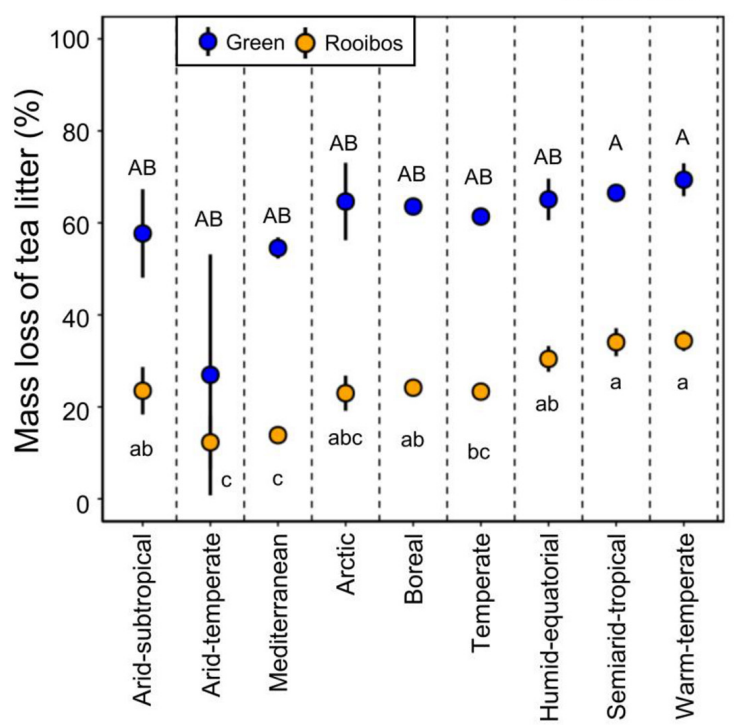

B

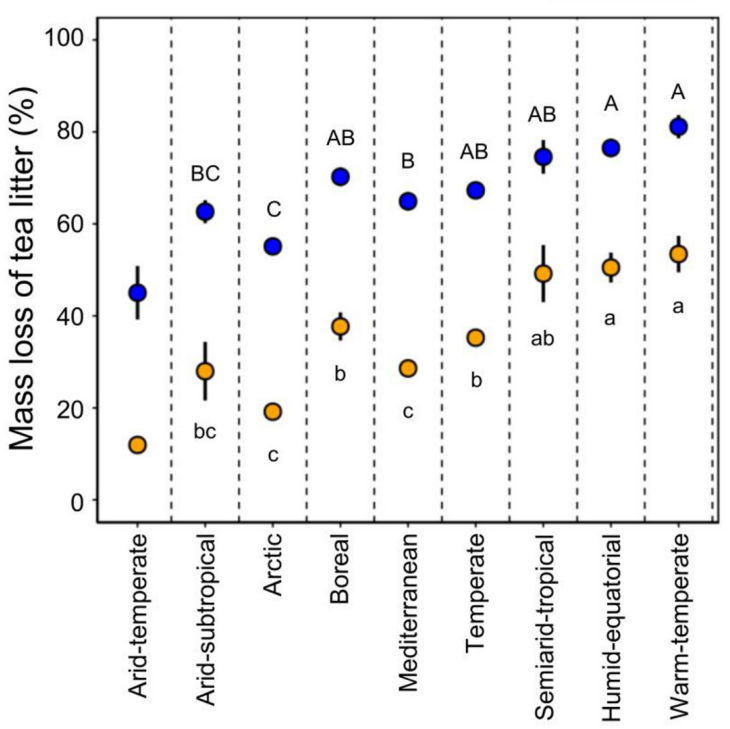

FIGURE 2 | Mass loss of tea litters (\%); Green tea (blue) and Rooibos tea (orange) after the field incubation of 3 (A) and 12 months (B) across biomes. Blue and orange circles show the means, and the bars are the standard errors based on the total number of observations. Uppercase and lowercase letters denote significant differences among biomes for Green and Rooibos tea, respectively, based on a Kruskal-Wallis test $(p<0.05)$. The order of biomes follows the order of mean monthly precipitation ( $\mathrm{mm} \mathrm{month}^{-1}$ ) for $\mathbf{( A )}$ and mean annual precipitation ( $\left.\mathrm{mm}_{\text {year }}{ }^{-1}\right)$ for $\mathbf{( B )}$ ). In case that the number of sites is $<3$ sites at each biome, then the data were not included in statistical analysis (i.e., Arid-temperate).

TABLE 3 | The effects of climatic factors and N deposition on the mass loss of Green tea and Rooibos tea after 3 and 12 months of incubation in all biomes.

\begin{tabular}{|c|c|c|c|c|c|c|c|c|c|c|c|}
\hline \multirow[b]{2}{*}{ Tea type } & \multirow[b]{2}{*}{ Fixed effects } & \multicolumn{5}{|c|}{ 3-month incubation in all biomes } & \multicolumn{5}{|c|}{ 12-month incubation in all biomes } \\
\hline & & Est. (SE) & $t$ & $P$ & Expl. (\%) & $\mathrm{R} 2 \mathrm{~m} / \mathrm{R} 2 \mathrm{c}$ & Est. (SE) & $t$ & $P$ & Expl. (\%) & $\mathrm{R} 2 \mathrm{~m} / \mathrm{R} 2 \mathrm{c}$ \\
\hline \multirow[t]{4}{*}{ Both } & Tea type & $38.69(0.21)$ & 186.60 & $<0.001$ & 72.5 & 0.74/0.89 & $32.65(0.25)$ & 129.84 & $<0.001$ & 61.8 & $0.69 / 0.84$ \\
\hline & Precipitation & $64.33(9.67)$ & 6.65 & $<0.001$ & 1.6 & & $7.33(1.02)$ & 7.23 & $<0.001$ & 2.3 & \\
\hline & Temperature & $0.21(0.10)$ & 2.15 & $<0.05$ & 0.2 & & $0.61(0.06)$ & 10.02 & $<0.001$ & 4.4 & \\
\hline & N deposition & - & - & - & - & - & $0.23(0.08)$ & 2.88 & $<0.01$ & 0.3 & \\
\hline \multirow[t]{2}{*}{ Green } & Precipitation & $59.40(12.60)$ & 4.72 & $<0.001$ & 4.2 & 0.05/0.76 & 7.05 (1.08) & 6.50 & $<0.001$ & 8.2 & $0.20 / 0.74$ \\
\hline & Temperature & $0.29(0.13)$ & 2.30 & $<0.05$ & 0.9 & & $0.51(0.06)$ & 7.96 & $<0.001$ & 11.7 & \\
\hline \multirow[t]{3}{*}{ Rooibos } & Precipitation & 70.18 (8.75) & 8.02 & $<0.001$ & 9.2 & 0.10/0.63 & $7.20(1.23)$ & 5.85 & $<0.001$ & 5.9 & $0.23 / 0.67$ \\
\hline & Temperature & $0.18(0.09)$ & 2.08 & $<0.05$ & 0.6 & & $0.70(0.07)$ & 9.28 & $<0.001$ & 14.9 & \\
\hline & $\mathrm{N}$ deposition & - & - & - & - & - & $0.34(0.10)$ & 3.57 & $<0.001$ & 2.0 & \\
\hline
\end{tabular}

Mean monthly air temperature $\left({ }^{\circ} \mathrm{C}\right)$, precipitation $\left(\mathrm{mm} \mathrm{month}^{-1}\right)$, and $\mathrm{N}$ deposition $\left(\mathrm{kg} \mathrm{N}^{\mathrm{N}} \mathrm{a}^{-1} \mathrm{month}^{-1}\right)$ were used for the analyses of samples incubated for 3 months, while mean annual air temperature $\left({ }^{\circ} \mathrm{C}\right)$, precipitation $\left(\mathrm{mm}\right.$ year $\left.{ }^{-1}\right)$, and $\mathrm{N}$ deposition $\left(\mathrm{kg} \mathrm{N} \mathrm{ha}^{-1}\right.$ year $\left.{ }^{-1}\right)$ were used for the analyses of samples incubated for $12 \mathrm{months}$. Est. (SE) = estimates (standard error), Expl. (\%) = variance percentage explained by each fixed factor. $R 2 m$ and $R 2 c$ are mean marginal $R^{2}$ and conditional $R^{2}$, respectively. Only significant fixed effects are shown. For precipitation, models were fitted with precipitation/1000 to avoid too small estimates.

to type of tea (explaining $79.2 \%$ of the variance), precipitation $(0.4 \%)$ and temperature $(0.3 \%)$, and negatively to $\mathrm{N}$ deposition $(0.7 \%)$ (Table 4$)$. When the analysis was run for each tea type separately, the 3-month mass loss of Green tea was affected by precipitation $(2.4 \%$, positively), temperature (3.8\%, positively), and $\mathrm{N}$ deposition (6.3\%, negatively), while the mass loss of Rooibos tea was affected by precipitation (2.1\%, positively) and $\mathrm{N}$ deposition $(1.3 \%$, negatively) without the relationship to temperature.
With the progress of decomposition (12 months), we observed further a positive correlation with tea type (explaining $68.2 \%$ of the variance) and temperature $(5.0 \%)$ as well as a negative correlation with the $\mathrm{N}$ deposition (1.7\%). However, the precipitation effect was missing (Table 4). When tea types were analyzed separately, also a positive correlation of mass loss with temperature (15.4\% for Green tea and $11.0 \%$ for Rooibos tea) and a negative correlation between mass loss and $\mathrm{N}$ deposition (9.5\% for Green tea and $1.1 \%$ for Rooibos tea) were recorded. 


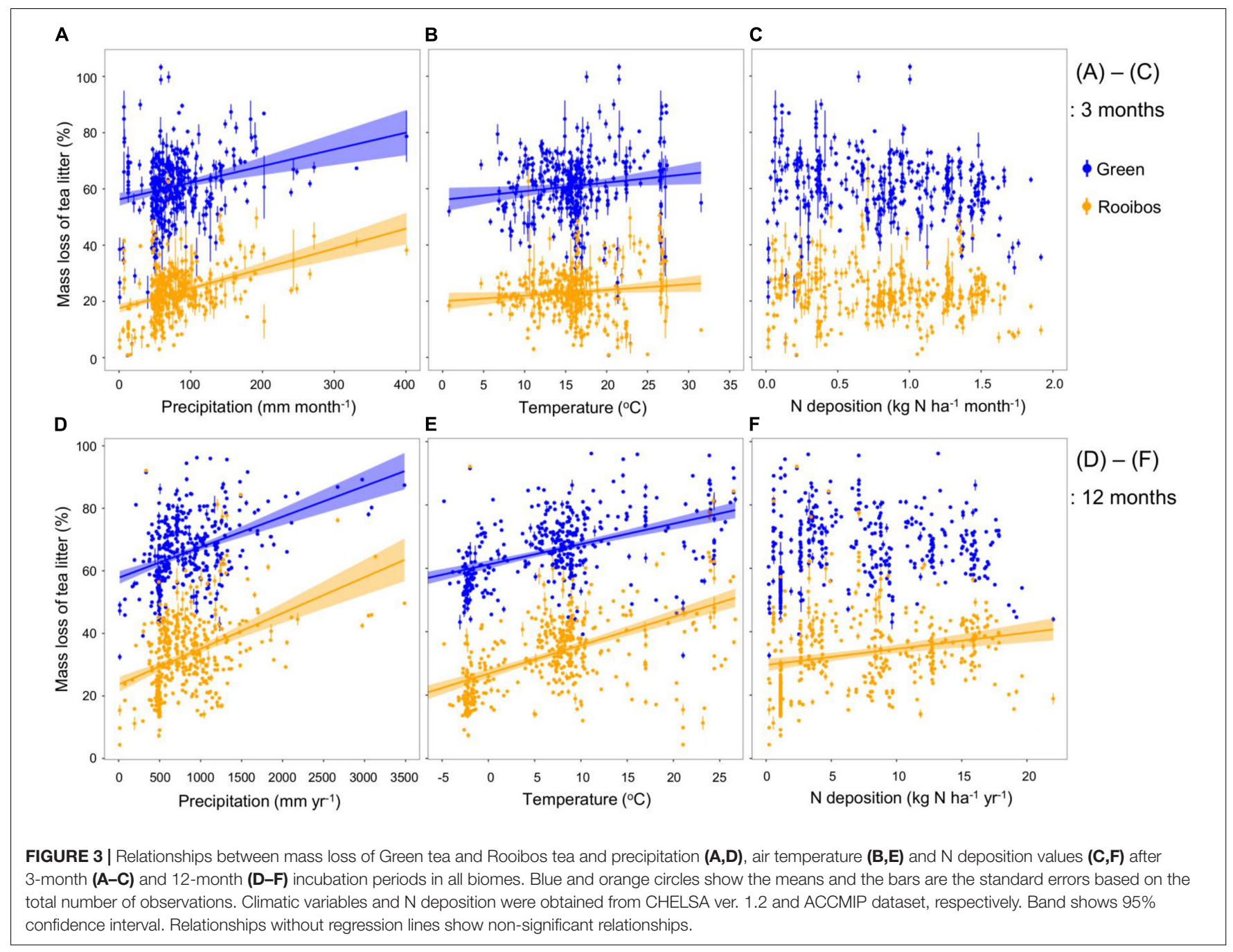

TABLE 4 | The effects of climatic factors and N deposition on the mass loss of Green tea and Rooibos tea after 3 and 12 months of incubation in the temperate biome.

\begin{tabular}{|c|c|c|c|c|c|c|c|c|c|c|c|}
\hline \multirow[b]{2}{*}{ Tea type } & \multirow[b]{2}{*}{ Fixed effects } & \multicolumn{5}{|c|}{ 3-month incubation in temperate climate } & \multicolumn{5}{|c|}{ 12-month incubation in temperate climate } \\
\hline & & Est. (SE) & $t$ & $P$ & Expl. (\%) & $\mathrm{R} 2 \mathrm{~m} / \mathrm{R} 2 \mathrm{c}$ & Est. (SE) & $t$ & $P$ & Expl. (\%) & $\mathrm{R} 2 \mathrm{~m} / \mathrm{R} 2 \mathrm{c}$ \\
\hline & Precipitation & $42.44(12.30)$ & 3.45 & $<0.001$ & 0.4 & & - & - & - & - & \\
\hline & Temperature & $0.37(0.13)$ & 2.75 & $<0.01$ & 0.3 & & $1.13(0.12)$ & 9.19 & $<0.001$ & 5.0 & \\
\hline & $\mathrm{N}$ deposition & $-4.49(1.11)$ & -4.06 & $<0.001$ & 0.7 & & $-0.54(0.10)$ & -5.30 & $<0.001$ & 1.7 & \\
\hline \multirow[t]{3}{*}{ Green } & Precipitation & $50.63(15.76)$ & 3.21 & $<0.01$ & 2.4 & $0.13 / 0.75$ & - & - & - & - & $0.25 / 0.68$ \\
\hline & Temperature & $0.67(0.17)$ & 3.92 & $<0.001$ & 3.8 & & $1.20(0.14)$ & 8.86 & $<0.001$ & 15.4 & \\
\hline & $\mathrm{N}$ deposition & $-6.79(1.42)$ & -4.78 & $<0.001$ & 6.3 & & $-0.77(0.11)$ & -6.92 & $<0.001$ & 9.5 & \\
\hline \multirow[t]{2}{*}{ Rooibos } & Precipitation & $33.12(12.03)$ & 2.75 & $<0.01$ & 2.1 & $0.03 / 0.61$ & - & - & - & - & $0.12 / 0.49$ \\
\hline & Temperature & - & - & - & - & & $1.02(0.14)$ & 7.12 & $<0.001$ & 11.0 & \\
\hline
\end{tabular}

Mean monthly air temperature $\left({ }^{\circ} \mathrm{C}\right)$, precipitation $\left(\mathrm{mm}\right.$ month $\left.{ }^{-1}\right)$, and $\mathrm{N}$ deposition $\left(\mathrm{kg} \mathrm{N} \mathrm{ha}^{-1} \mathrm{month}^{-1}\right)$ were used for the analyses of samples incubated for 3 months, while mean annual air temperature $\left({ }^{\circ} \mathrm{C}\right)$, precipitation $\left(\mathrm{mm}\right.$ year $\left.{ }^{-1}\right)$, and $\mathrm{N}$ deposition $\left(\mathrm{kg} \mathrm{N} \mathrm{ha}^{-1}\right.$ year $\left.{ }^{-1}\right)$ were used for the analyses of samples incubated for 12 months. Est. $(S E)=$ estimates (standard error), Expl. $(\%)=$ variance percentage explained by each fixed factor. $R 2 m$ and $R 2 c$ are mean marginal $R^{2}$ and conditional $R^{2}$, respectively. Only significant fixed effects are shown. For precipitation, models were fitted with precipitation/1000 to avoid too small estimates. 


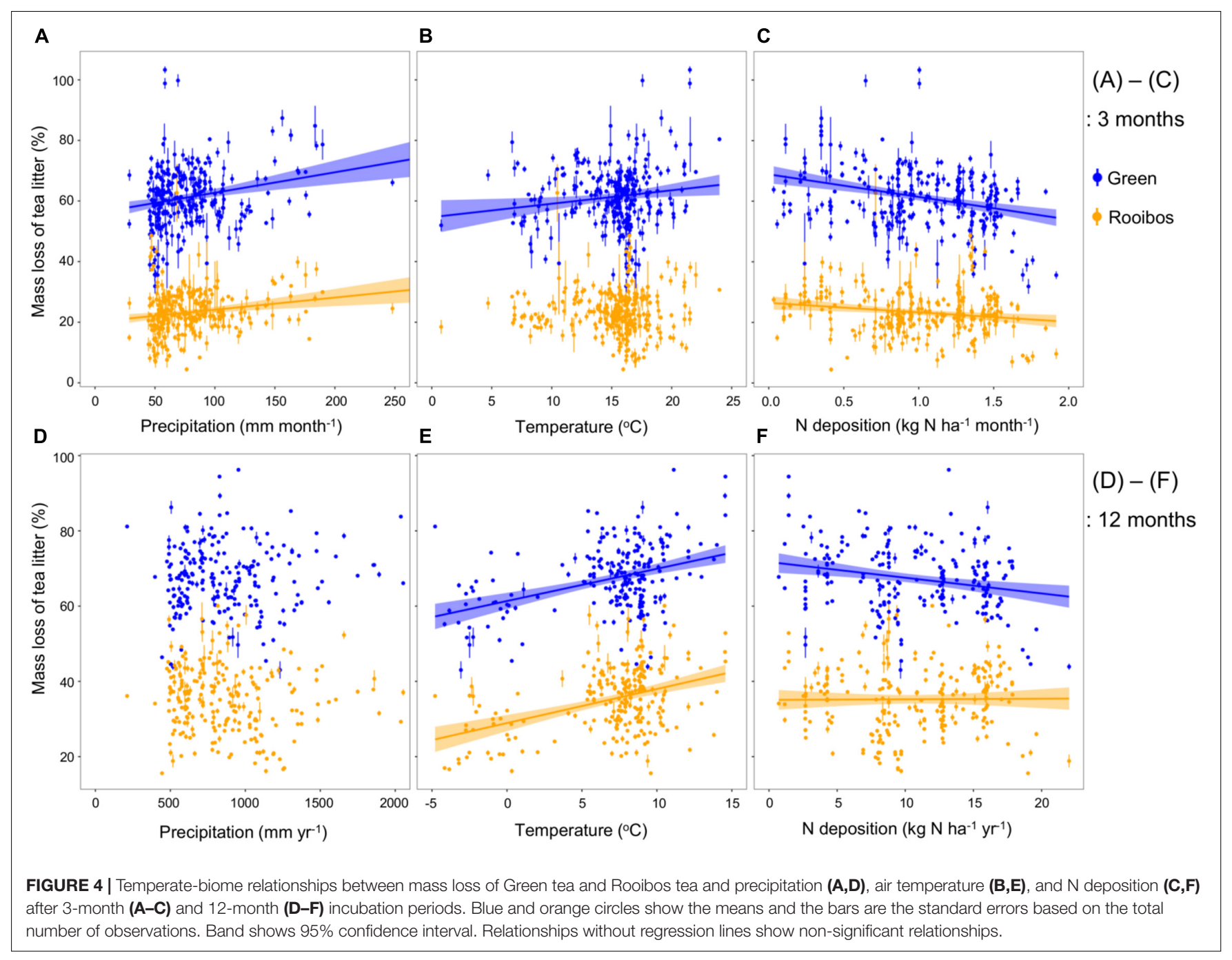

No significant effect of precipitation was observed for Green and Rooibos teas (Table 4 and Figure 4).

\section{Effects of Projected Future Climate and N Deposition on Litter Decomposition}

\section{Across All Biomes}

We investigated the effects of future climate scenarios (RCP 2.6 and RCP 8.5; Table 2) on the overall tea mass loss for the 12 -month incubation. Across all biomes, we found a $2.2-6.2 \%$ increase in predicted mass loss (relative to mass loss in current period) for both types (Table 5). In general, the predicted increase in mass loss appeared to be higher under the RCP 8.5 (3.5$10.6 \%)$ than under RCP 2.6 scenario $(<3.8 \%)$. Positive effects of increased air temperature on mass loss of both litter types were 3.0-4.9 times and 2.0-5.5 times higher than those of the predicted change in precipitation and $\mathrm{N}$ deposition, respectively. We noticed a much higher increase in mass loss for the litter material of Rooibos tea (3.8-10.6\%) as compared to the more labile litter of Green tea (1.1-3.5\%). The effects of air temperature as compared to precipitation seem to be greater on the mass loss of the more stable material of Rooibos tea (3.3- to 5.7-fold greater) than those of the mass loss of more labile Green tea material (2.7- to 4.0-fold). In addition, mass loss of Rooibos tea increased by the increase of $\mathrm{N}$ deposition from $1.2 \%$ to $1.9 \%$.

\section{Decomposition in the Temperate Biome}

In the temperate biome, models predicted a $0.9-6.2 \%$ increase in mass loss (relative to the current conditions) for both types of tea (Table 5). In contrast to the global scale, we noticed only the effect of air temperature change $(2.2-8.1 \%)$ by RCP 2.6 and RCP 8.5, but not of precipitation, on the overall mass loss of both tea types. Similar to the global scale, the mass loss of the more stable Rooibos tea material showed much higher increase $(2.0-9.3 \%)$ than that of the more labile Green tea material $(0.4-4.4 \%)$. Further, the effect of air temperature on mass loss of Green tea (1.8-6.6\%) was slightly lower than on Rooibos tea (2.9-10.7\%). The predicted change of $\mathrm{N}$ deposition in the temperate biome reduced the mass loss of both teas $(1.3-2.0 \%)$, whereby the mass loss of the Green tea (1.4-2.2\%) appeared to be slightly more inhibited than that of Rooibos tea $(0.9-1.5 \%)$. 


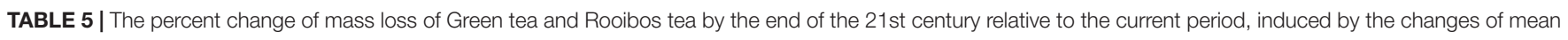
annual temperature (MAT), mean annual precipitation (MAP), and $\mathrm{N}$ deposition across all biomes and in the temperate biome after 1 year of decomposition.

\begin{tabular}{|c|c|c|c|c|c|c|}
\hline & \multicolumn{3}{|c|}{ All biomes } & \multicolumn{3}{|c|}{ Temperate biome } \\
\hline & Both teas & Green tea & Rooibos tea & Both teas & Green tea & Rooibos tea \\
\hline$\triangle \mathrm{MAT}$ & $1.2-4.4$ & $0.8-2.8$ & $2.0-7.4$ & $2.2-8.1$ & $1.8-6.6$ & $2.9-10.7$ \\
\hline$\triangle \mathrm{MAP}$ & $0.4-0.9$ & $0.3-0.7$ & $0.6-1.3$ & - & - & - \\
\hline$\Delta \mathrm{N}$ deposition & $0.6-0.8$ & - & $1.2-1.9$ & $-1.3--2.0$ & $-1.4--2.2$ & $-0.9--1.5$ \\
\hline Sum & $2.2-6.2$ & $1.1-3.5$ & $3.8-10.6$ & $0.9-6.2$ & $0.4-4.4$ & $2.0-9.3$ \\
\hline
\end{tabular}

\section{DISCUSSION}

Climate and $\mathrm{N}$ deposition effects on litter decomposition are complex and highly uncertain considering our present knowledge but of significant importance for the global carbon dynamics and assessment of future trajectories. The direct and indirect effects of these environmental changes on litter decomposition are not necessarily consistent between litter quality types (Coûteaux et al., 1995), decomposition stages (Berg, 2014), and environmental conditions (Delgado-Baquerizo et al., 2015; Frøseth and Bleken, 2015). Here we studied the mass loss as the decomposition degree of Green and Rooibos teas across 524 sites with contrasting climate and $\mathrm{N}$ deposition conditions. Our results show that litter quality $>$ climate $>\mathrm{N}$ deposition are key factors for litter decomposition, with litter quality being most important throughout the observation period, while the effects of climate and $\mathrm{N}$ deposition change over decomposition time and space.

\section{Impacts of Climate and N Deposition on Litter Mass Loss}

The abiotic and biotic factors regulating decomposition can change over time (Berg and McClaugherty, 2020; Canessa et al., 2021). In our study, litter quality explained a major part of the variance in mass loss both after 3 months (73\%) and 12 months (62\%) of incubation on the global scale. This is in accordance with several studies showing a positive relationship between litter quality and mass loss or decomposition rate (Zhang et al., 2008; Kang et al., 2009; Djukic et al., 2018; Fanin et al., 2020; Canessa et al., 2021). However, the extent of the effects of climatic variables changed with the stage of decomposition, with precipitation being most important during the 3-month incubation and the air temperature during 12 months of incubation for Green and Rooibos teas. A possible reason for this observation may be due to the fact that initial incubation occurred in the summer months, when precipitation was likely the main limiting factor for the majority of biomes (Prescott, 2010). Moreover, temperature variations during the summer months are smaller compared to the entire year (Karger et al., 2017), and the limiting factor for decomposition during dry seasons is water availability. In addition, during the initial decomposition phase, litter mass loss is dominated by the leaching of soluble compounds (e.g., Hagedorn and Machwitz, 2007; Djukic et al., 2018; Mori et al., 2020; TrevathanTackett et al., 2020), which is controlled by precipitation (Ristok et al., 2017). In later stages of decomposition, the microbial degradation of more stable components becomes increasingly important, which depends on both air temperature and precipitation (e.g., Davidson and Janssens, 2006). Rather optimal ranges between air temperature and precipitation were likely responsible for the high mass loss of both tea types as observed for the warm-temperate, humid-equatorial, and semiarid-tropical climates. In contrast, the extreme ranges of temperature and/or precipitation are likely to explain the low mass loss of both tea types at arid-temperate, arid-subtropical, and arctic climates.

In our study, the effect of $\mathrm{N}$ deposition was litter-specific, and only of significant importance for Rooibos tea during the 12 -month period at the global scale. Previous studies have shown that $\mathrm{N}$ effects on litter decomposition can be positive, negative, or near zero, depending on litter quality, degree of decomposition, as well as $\mathrm{N}$ saturation status of the ecosystems (Knorr et al., 2005; Hobbie, 2008; Prescott, 2010; Berg, 2014). The observed positive effect of $\mathrm{N}$ deposition on the mass loss of Rooibos tea $(\sim 35 \%)$ after 12 months, can be related to the stimulated decomposition of the more labile cellulose substrate through the N deposition (Wang et al., 2019; Berg and McClaugherty, 2020) during the early stage of decomposition (0-30\% mass loss). In contrast, the progressed decomposition of Green tea ( $\sim 66 \%$ of mass loss) is likely limited by the carbon and nutrient accessibility in the remaining litter, which are essential for the microbial function at the later stage of decomposition (Fanin et al., 2020). In addition, large variability in microclimatic conditions at the global scale as well as very coarse resolution of the available $\mathrm{N}$ deposition data $(\sim 100 \mathrm{~km})$ is likely masking the effect of $\mathrm{N}$ deposition. Hence, it is therefore necessary to consider the variability in the $\mathrm{N}$ deposition at the narrower spatial scale for the better understanding of the global decomposition processes.

In the temperate biome, we observed a negative relationship between $\mathrm{N}$ deposition and mass loss of both tea types after 3 and 12 months of incubation. Knorr et al. (2005) showed that ecosystems with $\mathrm{N}$ deposition rates between 5 and $10 \mathrm{~kg} \mathrm{~N} \mathrm{ha}^{-1}$ year $^{-1}$ experience an inhibitory effect on litter decomposition. The high $\mathrm{N}$ inputs might decrease the demand of decomposers to acquire litter-derived $\mathrm{N}$, when they are supplied with external N. Especially in the progressed decomposition stage, high $\mathrm{N}$ inputs may suppress the activity of lignolytic fungi and their oxidative enzymes and consequently suppress decomposition processes (Carreiro et al., 2000; Hobbie, 2008; Hobbie et al., 2012; Berg and McClaugherty, 2020).

Our study underlines the importance of considering the effects of different drivers in time and space for a better 
understanding of litter decomposition processes. Especially analyses of litter chemistry, soil properties, soil biodiversity, and their interactive effects (Mori et al., 2021) on decomposition processes are crucial for improved understanding of this fundamental biogeochemical process.

\section{Impacts of Predicted Climate and Atmospheric N Deposition on the Decomposition Process}

Our analyses of 1-year mass loss indicate that the expected changes in macroclimate by 2100 at the global scale will increase the mass loss of Green and Rooibos tea. The mass loss of more stable litter seems to be more affected by future warming than that of easily decomposable substrates (Table 5). The intrinsic temperature sensitivity is closely related to the molecular structure of the substrate and increases with its increasing molecular complexity (Davidson and Janssens, 2006), which is also in accordance with our findings across heterogeneous soil environments. However, several other environmental constraints on litter decomposition (such as $\mathrm{N}$ deposition) need to be discussed within the context of climate change. Future atmospheric $\mathrm{N}$ deposition is expected to have a strong effect on soil biogeochemical processes (Gaudio et al., 2015). In our study, the predicted increase in $\mathrm{N}$ deposition by 2100 shows also an enhancing effect on the mass loss of Rooibos tea at the global scale. Moreover, when taking into consideration the combined effects of organic $\mathrm{N}$ deposition ( $~ 30 \%$ of total $\mathrm{N}$ deposition globally; Neff et al., 2002; Cornell, 2011) and inorganic $\mathrm{N}$ deposition on litter decomposition, the effect of the total $\mathrm{N}$ deposition may be higher than our calculated estimates. Thus, the accelerated mineralization of the more stable substrate through the increase in temperature and $\mathrm{N}$ deposition might have profound implication for the global $\mathrm{C}$ budget. In turn, climate warming as well as higher $\mathrm{N}$ deposition might lead to a shift in the structure of plant communities (Cornelissen et al., 2007), changes in microclimate (Wang et al., 2019), increases in plant growth (Prescott, 2005; Bobbink et al., 2010; Bringmark et al., 2011; Fröberg et al., 2011), changes in litter quality [e.g., increase of litter N (Henry et al., 2005)], changes in soil C:N ratio (Mulder et al., 2015), and changes in soil microbial communities (Carreiro et al., 2000; Hobbie et al., 2012; Leff et al., 2015) with a potentially compensating effect of litter $\mathrm{C}$ mineralization.

In the temperate biome with higher average annual $\mathrm{N}$ deposition compared with other biomes, however, the predicted change in $\mathrm{N}$ deposition may lead to a decrease in mass loss of both high- and low-quality litters. Thus, the negative effect of $\mathrm{N}$ deposition on litter mass loss might mitigate, but not offset, the climate change-induced increase of litter decomposition at the regional level (cf. Berg, 2014). The effects of increased $\mathrm{N}$ deposition were quite small (means $1-2 \%$ ) relative to the effect of increased temperature (means 2-8\%) and probably irrelevant for plant species occurrence (Dirnböck et al., 2017). Moreover, Forstner et al. (2019) concluded that an accumulation of soil organic carbon in the organic layer through $\mathrm{N}$ addition in temperate forests might be even more sensitive to the $\mathrm{CO}_{2}$ release in case of disturbances or changing environmental conditions due to the lower degree of physicochemical protection of this soil layer.

Hence assessing the effects of co-occurring global change factors on biogeochemical processes at different geographical scales (e.g., Forstner et al., 2019; Rillig et al., 2019; Bowler et al., 2020) are of significant importance for understanding the relationships between $\mathrm{C}$ and $\mathrm{N}$ dynamics during different stages of litter decomposition.

\section{CONCLUSION}

Our results suggest that litter quality and climate were the most significant drivers of early-to-mid-stage litter decomposition. In addition, climate change and the excess of $\mathrm{N}$ deposition might accelerate the decomposition of more stable substrate at the global scale. However, at the regional scale future $\mathrm{N}$ deposition seems to have the capacity to dampen the predicted climate change effect. Studying the litter decomposition process over different time and spatial scales requires consideration of complex interplay of different parameters. For a better understanding of global and regional litter decomposition dynamics, we need to increase our basic knowledge on litterecosystem interactions in particular on the role of litter chemistry, soil properties (Wang et al., 2019), and biodiversity in decomposition process (Crowther et al., 2019). Moreover, pulsed nature of precipitation and temperature events rather than average annual values needs to be taken into the consideration for the certain biomes (Currie et al., 2010). Considering that the driving factors of litter decomposition at the global scale do not necessarily reflect those at the regional or local scale, a more representative site distribution across the globe is needed to address knowledge gaps in the decomposition process in future studies (Virkkala et al., 2019). There is also a need for better N-deposition products at high spatial and temporal resolutions to capture its variability significant for understanding of $\mathrm{N}$-deposition-decomposition relationships.

Our study indicates that global collaborative research with standard protocols such as the TeaComposition initiative is a powerful approach for global synthesis. Through the collaborative efforts, the valuable add-ons to the ongoing TeaComposition work will be included such as analyses of litter chemistry and soil biodiversity (e.g., Soil BON, Guerra et al., 2021) relevant for a comprehensive understanding of litter decomposition under climate change and atmospheric $\mathrm{N}$ pollution.

\section{MEMBERS OF THE TEACOMPOSITION NETWORK}

TaeOh Kwon, Field Science Center for Northern Biosphere, Hokkaido University, Sapporo, Japan; Hideaki Shibata, Field Science Center for Northern Biosphere, Hokkaido University, Sapporo, Japan; Sebastian Kepfer-Rojas, Department of Geosciences and Natural Resource Management, University 
of Copenhagen, Frederiksberg, Denmark; Inger Kappel Schmidt, Department of Geosciences and Natural Resource Management, University of Copenhagen, Frederiksberg, Denmark; Klaus Steenberg Larsen, Department of Geosciences and Natural Resource Management, University of Copenhagen, Frederiksberg, Denmark; Claus Beier, Department of Geosciences and Natural Resource Management, University of Copenhagen, Frederiksberg, Denmark; Björn Berg, Department of Forest Sciences, University of Helsinki, Helsinki, Finland; Kris Verheyen, Forest \& Nature Lab, Department of Forest and Water Management, Ghent University, Ghent, Belgium; Jean Francois Lamarque, National Center for Atmospheric Research, Boulder, CO, United States; Frank Hagedorn, Swiss Federal Institute for Forest, Snow and Landscape Research, Birmensdorf, Switzerland; Nico Eisenhauer, German Centre of Integrative Biodiversity Research (iDiv) Halle-Jena-Leipzig, Leipzig, Germany; Institute of Biology, Leipzig University, Leipzig, Germany; Ika Djukic, Swiss Federal Institute for Forest, Snow and Landscape Research, Birmensdorf, Switzerland; Adriano Caliman, Departamento de Ecologia, Centro de Biociências, Universidade Federal do Rio Grande do Norte, Natal, Brazil; Alain Paquette, Centre for Forest Research, Université du Québec à Montréal, Montreal, QC, Canada; Alba Gutiérrez-Girón, Department of Biodiversity, Ecology and Evolution, Complutense University, Madrid, Spain; Alessandro Petraglia, Department of Chemistry, Life Sciences and Environmental Sustainability, University of Parma, Parma, Italy; Algirdas Augustaitis, Faculty of Forest Sciences and Ecology, Academy of Agriculture, Vytautas Magnus University, Kaunas, Lithuania; Amélie Saillard, Université Grenoble Alpes, Université Savoie Mont Blanc, CNRS, LTSER ZAA, LECA, Grenoble, France; Ana Carolina Ruiz-Fernández, Unidad Académica Mazatlán, Instituto de Ciencias del Mar y Limnología, Universidad Nacional Autónoma de México, Mazatlán, Mexico; Ana I. Sousa, Centre for Environmental and Marine Studies, Department of Biology, University of Aveiro, Santiago University Campus, Aveiro, Portugal; Ana I. Lillebø, Centre for Environmental and Marine Studies, Department of Biology, University of Aveiro, Santiago University Campus, Aveiro, Portugal; Anderson da Rocha Gripp, Institute of Biodiversity and Sustainability (NUPEM), Federal University of Rio de Janeiro, Rio de Janeiro, Brazil; Andrea Lamprecht, GLORIA-Coordination, Austrian Academy of Sciences (Institute for Interdisciplinary Mountain Research), Vienna, Austria; GLORIA-Coordination, University of Natural Resources and Life Sciences Vienna (Department of Integrative Biology and Biodiversity Research), Vienna, Austria; Andreas Bohner, Agricultural Research and Education Centre Raumberg, IrdningDonnersbachtal, Austria; André-Jean Francez, Université de Rennes 1, CNRS, ECOBIO - UMR 6553 \& LTSER ZAAR, Rennes, France; Andrey Malyshev, Experimental Plant Ecology, Institute of Botany and Landscape Ecology, University of Greifswald, Greifswald, Germany; Andrijana Andrić, BioSense Institute, University of Novi Sad, Novi Sad, Serbia; Angela Stanisci, Department Bioscience and Territory, University of Molise, Termoli, Italy; Anita Zolles, Department of Forest Growth, Silviculture and Genetics, Austrian Research Centre for Forests, Vienna, Austria; GLORIA-Coordination, Austrian Academy of
Sciences (Institute for Interdisciplinary Mountain Research), Vienna, Austria; Anna Avila, Centre for Research on Ecology and Forestry Applications, Autonomous University of Barcelona, Catalonia, Spain; Anna-Maria Virkkala, Woodwell Climate Research Center, Falmouth, MA, United States; Department of Geosciences and Geography, Faculty of Science, University of Helsinki, Helsinki, Finland; Anne Probst, Laboratoire écologie fonctionnelle et environnement, Université de Toulouse, CNRS, Toulouse INP, Université Toulouse 3 - Paul Sabatier, Toulouse, France; LTSER Zone Atelier Pyrénées-Garonne, CNRS, University of Toulouse, Toulouse, France; Annie Ouin, UMR DYNAFOR (INRAE/INP de Toulouse), Avenue de l'Agrobiopole \& LTSER ZA PYGAR, Castanet-Tolosan, France; Anzar A. Khuroo, Centre for Biodiversity \& Taxonomy, Department of Botany, University of Kashmir, Srinagar, India; Arne Verstraeten, Research Institute for Nature and Forest, Geraardsbergen, Belgium; Artur Stefanski, Department of Forest Resources, University of Minnesota, St. Paul, MN, United States; Aurora Gaxiola, Departamento de Ecología, Pontificia Universidad Católica de Chile, Santiago \& Instituto de Ecología y Biodiversidad, Santiago, Chile; Bart Muys, Department of Earth and Environmental Sciences, KU Leuven, Leuven, Belgium; Beatriz Gozalo, Instituto Multidisciplinar del Estudio del Medio Ramón Margalef, Edificio Nuevos Institutos, Universidad de Alicante, Alicante, Spain; Bernd Ahrends, Northwest German Forest Research Institute, Department of Environmental Control, Göttingen, Germany; Bo Yang, Jiangxi Key Laboratory of Plant Resources and Biodiversity, Jingdezhen University, Jingdezhen, China; Brigitta Erschbamer, Department of Botany, University of Innsbruck, Innsbruck, Austria; Carmen Eugenia Rodríguez Ortíz, Department of Botany and Ecology, Institute of Biosciences, Federal University of Mato Grosso, Cuiabá, Brazil; Casper T. Christiansen, Terrestrial Ecology Section, Department of Biology, University of Copenhagen, Copenhagen, Denmark; Norwegian Research Centre, Bjerknes Centre for Climate Research, Bergen, Norway; Céline Meredieu, INRAE, Université de Bordeaux, Cestas, France; Cendrine Mony, Université de Rennes 1, CNRS, ECOBIO - UMR 6553 \& LTSER ZAAR, Rennes, France; Charles Nock, Department of Renewable Resources, University of Alberta, Edmonton, $A B$, Canada; Chiao-Ping Wang, Division of Silviculture, Taiwan Forest Research Institute, Taipei, Taiwan; Christel Baum, Soil Science, University of Rostock, Rostock, Germany; Christian Rixen, WSL Institute for Snow and Avalanche Research SLF, Davos Dorf, Switzerland; Christine Delire, Centre National de Recherches Météorologiques, UMR3589 Université de Toulouse/Météo-France/CNRS, Toulouse, France; Christophe Piscart, Université de Rennes 1, CNRS, ECOBIO - UMR 6553 \& LTSER ZAAR, Rennes, France; Christopher Andrews, UK Centre for Ecology \& Hydrology, Penicuik, United Kingdom; Corinna Rebmann, Department of Computational Hydrosystems, Helmholtz Centre for Environmental Research GmbH - UFZ, Leipzig, Germany; Cristina Branquinho, Centre for Ecology, Evolution and Environmental Changes, Faculdade de Ciências, Universidade de Lisboa, Lisboa, Portugal; Dick Jan, UK Centre for Ecology \& Hydrology, Penicuik, United Kingdom; Dirk Wundram, Department of Geography, University of Bonn, 
Bonn, Germany; Dušanka Vujanović, BioSense Institute, University of Novi Sad, Novi Sad, Serbia; E. Carol Adair, Rubenstein School of Environment and Natural Resources, University of Vermont, Burlington, VT, United States; Eduardo Ordóñez-Regil, Chemistry Department, Instituto Nacional de Investigaciones Nucleares, Ocoyoacac, Mexico; Edward R. Crawford, Virginia Commonwealth University Rice Rivers Center, Charles City County, VA, United States; Elena F. Tropina, National Park "Krasnoyarsk Stolby" (Nature Reserve "Stolby" until 2019), Krasnoyarsk, Russia; Elisabeth Hornung, Institute for Biology, University of Veterinary Medicine Budapest, Budapest, Hungary; Elli Groner, Dead Sea and Arava Science Center, Mitzpe Ramon, Israel; Eric Lucot, Université de Franche-Comté - CNRS - UMR Chrono-Environnement, Besançon, France; Esperança Gacia, Centre d'Estudis Avançats de Blanes, CSIC Ctra, Blanes, Spain; Esther Lévesque, Université du Québec à Trois-Rivières, Trois-Rivières, QC, Canada; Evanilde Benedito, Postgraduate Program in Ecology and Freshwater Environments, State University of Maringá, Maringá, Brazil; Evgeny A. Davydov, Altai State University, Barnaul, Russia; Tigirek State Natural Reserve, Barnaul, Russia; Fábio Padilha Bolzan, Universidade Federal de Mato Grosso do Sul, Centro de Ciências Biológicas e da Saúde, Campo Grande, Brazil; Fernando T. Maestre, Departamento de Ecología, Universidad de Alicante, San Vicente del Raspeig, Spain; Instituto Multidisciplinar del Estudio del Medio Ramón Margalef, Edificio Nuevos Institutos, Universidad de Alicante, Alicante, Spain; Florence Maunoury-Danger, Université de Lorraine, CNRS, Laboratoire Interdisciplinaire des Environnements Continentaux \& LTSER ZAM, Metz, France; Florian Kitz, Department of Ecology, University of Innsbruck, Innsbruck, Austria; Florian Hofhansl, International Institute for Applied Systems Analysis, Laxenburg, Austria; Flurin Sutter, Swiss Federal Research Institute WSL, Birmensdorf, Switzerland; Francisco de Almeida Lobo, Department of Soils and Rural Engineering, Faculty of Agronomy and Zootechnics, Federal University of Mato Grosso, Cuiabá, Brazil; Franco Leadro Souza, Universidade Federal de Mato Grosso do Sul, Centro de Ciências Biológicas e da Saúde, Campo Grande, Brazil; Franz Zehetner, Institute of Soil Research, University of Natural Resources and Life Sciences, Vienna, Austria; Galápagos National Park Directorate, Santa Cruz, Galápagos, Ecuador; Fulgence Kouamé Koffi, Nangui Abrogoua University (ex University of Abobo-Adjamé), Abidjan, Côte d'Ivoire; Georg Wohlfahrt, Department of Ecology, University of Innsbruck, Innsbruck, Austria; Giacomo Certini, Dipartimento di Scienze e Tecnologie Agrarie, Alimentari, Ambientali e Forestali, Università di Firenze, Firenze, Italy; Gisele Daiane Pinha, State University of Maringá, Maringá, Brazil; Grizelle González, International Institute of Tropical Forestry, USDA Forest Service, Río Piedras, Puerto Rico; Guylaine Canut, Centre National de Recherches Météorologiques, UMR3589 Université de Toulouse/Météo-France/CNRS, Toulouse, France; Harald Pauli, GLORIA-Coordination, Austrian Academy of Sciences (Institute for Interdisciplinary Mountain Research), Vienna, Austria; GLORIA-Coordination, University of Natural Resources and Life Sciences Vienna (Department of Integrative Biology and Biodiversity Research), Vienna, Austria; Héctor A. Bahamonde,
Instituto Nacional de Tecnología Agropecuaria, Universidad Nacional de la Patagonia Austral, Río Gallegos, Argentina; Heike Feldhaar, Animal Ecology I, Bayreuth Center for Ecology and Environmental Research, University of Bayreuth, Bayreuth, Germany; Heinke Jäger, Charles Darwin Research Station, Charles Darwin Foundation, Galápagos, Ecuador; Helena Cristina Serrano, Centre for Ecology, Evolution and Environmental Changes, Faculdade de Ciências, Universidade de Lisboa, Lisboa, Portugal; Hélène Verheyden, INRAE, CEFS, Université de Toulouse \& LTSER ZAPYGAR, Castanet Tolosan, France; Helge Bruelheide, Institute of Biology/Geobotany and Botanical Garden, Martin Luther University HalleWittenberg, Halle (Saale), Germany; German Centre of Integrative Biodiversity Research (iDiv) Halle-Jena-Leipzig, Leipzig, Germany; Henning Meesenburg, Northwest German Forest Research Institute, Department of Environmental Control, Göttingen, Germany; Hermann Jungkunst, iES LAndau, Institute for Environmental Sciences, University of Koblenz-Landau, Mainz, Germany; Hervé Jactel, INRAE, Université de Bordeaux, Cestas, France; Hiroko Kurokawa, Forestry and Forest Products Research Institute, Tsukuba, Japan; Ian Yesilonis, United States Department of Agriculture Forest Service, Baltimore, MD, United States; Inara Melece, Institute of Biology, University of Latvia, Riga, Latvia; Inge van Halder, INRAE, Université de Bordeaux, Cestas, France; Inmaculada García Quirós, Department of Computational Hydrosystems, Helmholtz Centre for Environmental Research GmbH - UFZ, Leipzig, Germany; István Fekete, Institute of Environmental Sciences, University of Nyíregyháza, Nyíregyháza, Hungary; Ivika Ostonen, Institute of Ecology and Earth Sciences, University of Tartu, Tartu, Estonia; Jana Borovská, Institute of Landscape Ecology of Slovak Academy of Sciences - Branch Nitra, Nitra, Slovakia; Javier Roales, Departamento de Sistemas Físicos, Químicos y Naturales, Universidad Pablo de Olavide, Seville, Spain; Jawad Hasan Shoqeir, Soil and Hydrology Research, Earth and Environmental Studies, Al-Quds University, Palestine; Jerusalem, Jean-Christophe Lata, Sorbonne Université, Université de Paris, UPEC, CNRS, INRA, IRD, UMR 7618, Institute of Ecology and Environmental Sciences - Paris, iEES Paris, Paris, France; Department of Geoecology and Geochemistry, Institute of Natural Resources, Tomsk Polytechnic University, Tomsk, Russia; Jean-Luc Probst, Laboratoire écologie fonctionnelle et environnement, Université de Toulouse, CNRS, Toulouse INP, Université Toulouse 3 - Paul Sabatier, Toulouse, France; LTSER Zone Atelier Pyrénées-Garonne, CNRS, University of Toulouse, Toulouse, France; Jeyanny Vijayanathan, Forest Research Institute of Malaysia, Kepong, Malaysia; Jiri Dolezal, Institute of Botany, The Czech Academy of Sciences, and Faculty of Science, University of South Bohemia, Ėeské Budijovice, Czechia; Joan-Albert Sanchez-Cabeza, Unidad Académica Mazatlán, Instituto de Ciencias del Mar y Limnología, Universidad Nacional Autónoma de México, Mazatlán, Mexico; Joël Merlet, INRAE, CEFS, Université de Toulouse \& LTSER ZAPYGAR, Castanet Tolosan, France; John Loehr, Faculty of Biological and Environmental Sciences, University of Helsinki, Lammi Biological Station, Lammi, Finland; Jonathan von Oppen, WSL Institute for Snow and Avalanche Research SLF, Davos 
Dorf, Switzerland; Jörg Löfler, Department of Geography, University of Bonn, Bonn, Germany; José Luis Benito Alonso, Department of Biodiversity and Ecosystem Restoration, Pyrenean Institute of Ecology, Spanish National Research Council, Victoria, Spain; José-Gilberto Cardoso-Mohedano, Estación el Carmen, Instituto de Ciencias del Mar y Limnología, Universidad Nacional Autónoma de México, Campeche, México; Josep Peñuelas, Centre for Research on Ecology and Forestry Applications, Autonomous University of Barcelona, Catalonia, Spain; Joseph C. Morina, Virginia Commonwealth University Rice Rivers Center, Charles City County, VA, United States; Juan Darío Quinde, Southern Federal University, Rostovon-Don, Russia; Centro de Investigaciones del Ambiente y Biodiversidad - CITIAB, Universidad Nacional de Loja, Loja, Ecuador; Juan J. Jiménez, Department of Biodiversity and Ecosystem Restoration, Pyrenean Institute of Ecology, Spanish National Research Council, Victoria, Spain; Juha M. Alatalo, Environmental Science Center, Qatar University, Doha, Qatar; Julia Seeber, Institute for Alpine Environment, Eurac Research, Bozen, Italy; Department of Ecology, University of Innsbruck, Innsbruck, Austria; Julia Kemppinen, Geography Research Unit, University of Oulu, Oulu, Finland; Jutta Stadler, Helmholtz Centre for Environmental Research-UFZ, Department of Community Ecology, Halle/Saale, Germany; Kaie Kriiska, Institute of Ecology and Earth Sciences, University of Tartu, Tartu, Estonia; Karel Van den Meersche, French Agricultural Research Centre for International Development, Montpellier, France; Karibu Fukuzawa, Field Science Center for Northern Biosphere, Hokkaido University, Sapporo, Japan; Katalin Szlavecz, Department of Earth and Planetary Sciences, Johns Hopkins University, Baltimore, MD, United States; Katalin Juhos, Department of Agro-Environmental Studies, Hungarian University of Agriculture and Life Sciences, Budapest, Hungary; Katarína Gerhátová, Institute of Landscape Ecology of Slovak Academy of Sciences - Branch Nitra, Nitra, Slovakia; Kate Lajtha, Department of Crop and Soil Sciences, Oregon State University, Corvallis, OR, United States; Katie Jennings, Earth Systems Research Center, University of New Hampshire, Durham, NH, United States; Katja Tielbörger, Plant Ecology, Institute for Evolution and Ecology, University of Tübingen, Tübingen, Germany; Kazuhiko Hoshizaki, Department of Biological Environment, Akita Prefectural University, Akita, Japan; Ken Green, College of Asia and the Pacific, Australian National University, Canberra, ACT, Australia; Klaus Steinbauer, Engineering \& IT, Carinthia University of Applied Sciences, Villach, Austria; GLORIA-Coordination, University of Natural Resources and Life Sciences Vienna (Department of Integrative Biology and Biodiversity Research), Vienna, Austria; Laryssa Pazianoto, Postgraduate Program in Ecology and Freshwater Environments, State University of Maringá, Maringá, Brazil; Laura Dienstbach, Department of Computational Hydrosystems, Helmholtz Centre for Environmental Research GmbH - UFZ, Leipzig, Germany; Laura Yahdjian, Instituto de Investigaciones Fisiológicas y Ecológicas Vinculadas a la Agricultura, Cátedra de Ecología, Facultad de Agronomía, Universidad de Buenos Aires, Buenos Aires, Argentina; Laura J. Williams, Department of Forest Resources, University of Minnesota, St. Paul, MN,
United States; Laurel Brigham, Department of Ecology and Evolutionary Biology, University of Colorado, Boulder, CO, United States; Lee Hanna, Norwegian Research Centre, Bjerknes Centre for Climate Research, Bergen, Norway; Liesbeth van den Brink, Plant Ecology, Institute for Evolution and Ecology, University of Tübingen, Tübingen, Germany; Lindsey Rustad, Northern Research Station, USDA Forest Service, Durham, NH, United States; Lourdes Morillas, Centre for Ecology, Evolution and Environmental Changes, Faculdade de Ciências, Universidade de Lisboa, Lisbon, Portugal; Luciana Silva Carneiro, Departamento de Ecologia, Centro de Biociências, Universidade Federal do Rio Grande do Norte, Natal, Brazil; Luciano Di Martino, Majella Seed Bank, Majella National Park, Lama dei Peligni, Italy; Luis Villar, Department of Biodiversity and Ecosystem Restoration, Pyrenean Institute of Ecology, Spanish National Research Council, Victoria, Spain; Luísa Alícida Fernandes Tavares, Institute of Biodiversity and Sustainability (NUPEM), Federal University of Rio de Janeiro, Rio de Janeiro, Brazil; Madison Morley, Department of Sustainable Resource Management, SUNY College of Environmental Science and Forestry, Syracuse, NY, United States; Manuela Winkler, GLORIA-Coordination, Austrian Academy of Sciences (Institute for Interdisciplinary Mountain Research), Vienna, Austria; GLORIA-Coordination, University of Natural Resources and Life Sciences Vienna (Department of Integrative Biology and Biodiversity Research), Vienna, Austria; Marc Lebouvier, University of Rennes, CNRS, ECOBIO [(Ecosystèmes, biodiversité, évolution)] - UMR 6553 \& LTSER ZATA, Rennes, France; Marcello Tomaselli, Department of Chemistry, Life Sciences and Environmental Sustainability, University of Parma, Parma, Italy; Marcus Schaub, Swiss Federal Research Institute WSL, Birmensdorf, Switzerland; Maria Glushkova, Forest Research Institute, Sofia, Bulgaria; Maria Guadalupe Almazan Torres, Chemistry Department, Instituto Nacional de Investigaciones Nucleares, Ocoyoacac, Mexico; Marie-Anne de Graaff, Department of Biological Sciences, Boise State University, Boise, ID, United States; Marie-Noëlle Pons, Université de Lorraine, CNRS, Laboratoire Réactions et Génie des Procédés \& LTSER ZAM, Nancy, France; Marijn Bauters, Department of Environment, Ghent University, Ghent, Belgium; Marina Mazón, Centro de Investigaciones del Ambiente y Biodiversidad - CITIAB, Universidad Nacional de Loja, Loja, Ecuador; Mark Frenzel, Helmholtz Centre for Environmental Research-UFZ, Department of Community Ecology, Halle/Saale, Germany; Markus Wagner, Northwest German Forest Research Institute, Department of Environmental Control, Göttingen, Germany; Markus Didion, Swiss Federal Research Institute WSL, Birmensdorf, Switzerland; Maroof Hamid, Centre for Biodiversity \& Taxonomy, Department of Botany, University of Kashmir, Srinagar, India; Marta Lopes, Centre for Environmental and Marine Studies, Department of Biology, University of Aveiro, Santiago University Campus, Aveiro, Portugal; Martha Apple, Department of Biological Sciences, Montana Technological University, Butte, MT, United States; Martin Weih, Department of Crop Production Ecology, Swedish University of Agricultural Sciences, Uppsala, Sweden; Matej Mojses, Institute of Landscape Ecology of Slovak Academy of Sciences - Branch Nitra, Nitra, 
Slovakia; Matteo Gualmini, Department of Chemistry, Life Sciences and Environmental Sustainability, University of Parma, Parma, Italy; Matthew Vadeboncoeur, Earth Systems Research Center, University of New Hampshire, Durham, NH, United States; Michael Bierbaumer, 4 Reichergasse 48, Klosterneuburg-Weidling, Austria; Michael Danger, Université de Lorraine, CNRS, Laboratoire Interdisciplinaire des Environnements Continentaux \& LTSER ZAM, Metz, France; Michael Scherer-Lorenzen, Faculty of Biology, Geobotany, University of Freiburg, Freiburg, Germany; Michal Rưžek, Czech Geological Survey, Department of Environmental Geochemistry and Biogeochemistry, Prague, Czechia; Department of Physical Geography and Geoecology, Faculty of Science, Prague, Czechia; Michel Isabellon, Environmental Protection Agency of Aosta Valley, ARPA Valle dAosta, Climate Change Unit, SaintChristophe, Italy; Michele Di Musciano, Department of Life Health and Environmental Science (MESVA), University of L'Aquila, L'Aquila, Italy; Michele Carbognani, Department of Chemistry, Life Sciences and Environmental Sustainability, University of Parma, Parma, Italy; Miglena Zhiyanski, Forest Research Institute, Sofia, Bulgaria; Mihai Puşcaş, Faculty of Biology and Geology, A. Borza Botanic Garden, E.G. Racoviţă Institute, Babeş-Bolyai University, Cluj-Napoca, Romania; Milan Barna, Institute of Forest Ecology, Slovak Academy of Sciences, Zvolen, Slovakia; Mioko Ataka, Forestry and Forest Products Research Institute (FFPRI), Kyoto, Japan; Miska Luoto, Department of Geosciences and Geography, Faculty of Science, University of Helsinki, Helsinki, Finland; Mohammed $\mathrm{H}$. Alsafaran, Department of Biological and Environmental Sciences, College of Arts and Sciences, Qatar University, Doha, Qatar; Nadia Barsoum, Centre for Ecosystems, Society and Biosecurity, Forest Research, Surrey, United Kingdom; Naoko Tokuchi, Field Science Education and Research Center, Kyoto, Japan; Nathalie Korboulewsky, INRAE, UR EFNO, Domaine des Barres, Nogentsur-Vernisson, France; Nicolas Lecomte, Canada Research Chair in Polar and Boreal Ecology and Center for Northern Studies, Department of Biology, Université de Moncton, Moncton, NB, Canada; Nina Filippova, Yugra State University, KhantyMansiyskiy, Russia; Norbert Hölzel, Institute of Landscape Ecology, University of Muenster, Münster, Germany; Olga Ferlian, German Centre of Integrative Biodiversity Research (iDiv) Halle-Jena-Leipzig, Leipzig, Germany; Institute of Biology, Leipzig University, Leipzig, Germany; Oscar Romero, Centro de Investigaciones del Ambiente y Biodiversidad CITIAB, Universidad Nacional de Loja, Loja, Ecuador; Grupo de Investigación en Biotecnología aplicada, Universidad Nacional Experimental Sur del Lago, Santa Bárbara del Zulia, Venezuela; Osvaldo Pinto-Jr, Environmental Sciences Program, Cuiabá University, Cuiaba, Brazil; Pablo Peri, Instituto Nacional de Tecnología Agropecuaria, Universidad Nacional de la Patagonia Austral, Río Gallegos, Argentina; Pavel Dan Turtureanu, A. Borza Botanic Garden, E.G. Racoviţǎ Institute, Center for Systematic Biology, Biodiversity and Bioresources - 3B, Babeş-Bolyai University, Cluj-Napoca, Romania; Peter Haase, Senckenberg Research Institute and Natural History Museum Frankfurt, Department of River Ecology and Conservation, Gelnhausen, Germany; Faculty of Biology, University of Duisburg-Essen,
Essen, Germany; Peter Macreadie, Centre for Integrative Ecology, School of Life and Environmental Sciences, Deakin University, Burwood, VIC, Australia; Peter B. Reich, Department of Forest Resources, University of Minnesota, St. Paul, MN, United States; Hawkesbury Institute for the Environment, Western Sydney University, Penrith, NSW, Australia; Petr Petřík, Institute of Botany, Czech Academy of Sciences, Pruhonice, Czechia; Philippe Choler, Université Grenoble Alpes, Université Savoie Mont Blanc, CNRS, LTSER ZAA, LECA, Grenoble, France; Pierre Marmonier, University of Lyon, Université Claude Bernard Lyon 1, CNRS, ENTPE, UMR 5023 LEHNA \& LTSER ZABR, Villeurbanne, France; Quentin Ponette, Faculty of Bioscience Engineering \& Earth and Life Institute, Université catholique de Louvain, Louvain-la-Neuve, Belgium; Rafael Dettogni Guariento, Universidade Federal de Mato Grosso do Sul, Centro de Ciências Biológicas e da Saúde, Campo Grande, Brazil; Rafaella Canessa, Ecological Plant Geography, Faculty of Geography, University of Marburg, Marburg, Germany; Ralf Kiese, Wrigley Global Institute of Sustainability, Arizona State University, Tempe, AZ, United States; Rebecca Hewitt, Boreal Ecology Cooperative Research Unit, University of Alaska Fairbanks, Fairbanks, AK, United States; Robert Weigel, Plant Ecology, Albrecht-von-Haller-Institute for Plant Sciences, University of Goettingen, Goettingen, Germany; Róbert Kanka, Institute of Landscape Ecology, Slovak Academy of Sciences, Bratislava, Slovakia; Roberto Cazzolla Gatti, Biological Institute, Tomsk State University, Tomsk, Russia; AGHYLE Research Unit, Polytechnical Institute UniLaSalle, Rouen, France; Rodrigo Lemes Martins, Institute of Biodiversity and Sustainability (NUPEM), Federal University of Rio de Janeiro, Rio de Janeiro, Brazil; Romà Ogaya, Centre for Research on Ecology and Forestry Applications, Autonomous University of Barcelona, Catalonia, Spain; Romain Georges, Université de Rennes 1, CNRS, ECOBIO - UMR 6553 \& LTSER ZAAR, Rennes, France; Rosario G. Gavilán, Department of Pharmacology, Pharmacognosy and Botany, Complutense University, Madrid, Spain; Sally Wittlinger, Central Arizona-Phoenix LTER, Global Institute of Sustainability and Innovation, Arizona State University, Tempe, AZ, United States; Sara Puijalon, University of Lyon, Université Claude Bernard Lyon 1, CNRS, ENTPE, UMR 5023 LEHNA \& LTSER ZABR, Villeurbanne, France; Satoshi Suzuki, The University of Tokyo Forest, The University of Tokyo, Tokyo, Japan; Schädler Martin, Department of Community Ecology, Helmholtz-Centre for Environmental Research, Halle, Germany; Schmidt Anja, Department of Community Ecology, Helmholtz-Centre for Environmental Research, Halle, Germany; Sébastien Gogo, Université d'Orléans, CNRS, BRGM, ISTO, UMR 7327 \& LTSER ZAL, Orléans, France; Silvio Schueler, Department of Forest Growth, Silviculture and Genetics, Austrian Research Centre for Forests, Vienna, Austria; GLORIACoordination, Austrian Academy of Sciences (Institute for Interdisciplinary Mountain Research), Vienna, Austria; Simon Drollinger, Department of Physical Geography, University of Göttingen, Göttingen, Germany; Simone Mereu, Department of BioEconomy, National Research Council, Sassari, Italy; Sonja Wipf, WSL Institute for Snow and Avalanche Research SLF, Davos Dorf, Switzerland; Stacey Trevathan-Tackett, Centre 
for Integrative Ecology, School of Life and Environmental Sciences, Deakin University, Burwood, VIC, Australia; Stefan Stoll, University of Applied Sciences Trier, Environmental Campus Birkenfeld, Birkenfeld, Germany; Stefan Löfgren, Department of Aquatic Sciences and Assessment, Swedish University of Agricultural University, Uppsala, Sweden; Stefan Trogisch, Institute of Biology/Geobotany and Botanical Garden, Martin Luther University Halle-Wittenberg, Halle (Saale), Germany; German Centre of Integrative Biodiversity Research (iDiv) Halle-Jena-Leipzig, Leipzig, Germany; Steffen Seitz, Soil Science and Geomorphology, University of Tübingen, Tübingen, Germany; Stephan Glatzel, Department of Geography and Regional Research, Geoecology, University of Vienna, Vienna, Austria; Susanna Venn, Centre for Integrative Ecology, School of Life and Environmental Sciences, Deakin University, Burwood, VIC, Australia; Sylvie Dousset, Université de Lorraine - CNRS - Laboratoire Interdisciplinaire des Environnements Continentaux \& LTSER ZAM, Vandoeuvre-lès-Nancy, France; Taiki Mori, South China Botanical Garden, Guangzhou, China; Takanori Sato, Akazu Research Forest, Ecohydrology Research Institute, The University of Tokyo Forests, Seto, Japan; Takuo Hishi, Shiiba Research Forest, Kyushu University, Miyazaki, Japan; Tatsuro Nakaji, Tomakomai Experimental Forest, Hokkaido University, Hokkaido, Japan; Theurillat Jean-Paul, Fondation J.-M. Aubert, Champex-Lac, Switzerland; Department of Botany and Plant Biology, University of Geneva, Chambésy, Switzerland; Thierry Camboulive, Laboratoire écologie fonctionnelle et environnement, Université de Toulouse, CNRS, Toulouse INP, Université Toulouse 3 - Paul Sabatier, Toulouse, France; LTSER Zone Atelier Pyrénées-Garonne, CNRS, University of Toulouse, Toulouse, France; Thomas Spiegelberger, Université Grenoble Alpes, INRAE, UR LESSEM \& LTSER ZAA, Grenoble, France; Thomas Scholten, Soil Science and Geomorphology, University of Tübingen, Tübingen, Germany; Thomas J. Mozdzer, Department of Biology, Bryn Mawr College, Bryn Mawr, PA, United States; Till Kleinebecker, Institute of Landscape Ecology and Resources Management, Justus-Liebig-Universität Gießen, Giessen, Germany; Tomáš Rusňák, Institute of Landscape Ecology of Slovak Academy of Sciences - Branch Nitra, Nitra, Slovakia; Tshililo Ramaswiela, South African Environmental Observation Network, Arid Lands Node, Kimberley, South Africa; Tsutom Hiura, Tomakomai Experimental Forest, Hokkaido University, Hokkaido, Japan; Tsutomu Enoki, Kasuya Research Forest, Kyushu University, Fukuoka, Japan; Tudor-Mihai Ursu, Institute of Biological Research, Department of Taxonomy and Ecology, National Institute of Research and Development for Biological Sciences, Cluj-Napoca, Romania; Umberto Morra di Cella, Environmental Protection Agency of Aosta Valley, ARPA Valle dAosta, Climate Change Unit, Saint-Christophe, Italy; Ute Hamer, Institute of Landscape Ecology, University of Muenster, Münster, Germany; Valentin Klaus, Institute of Agricultural Sciences, Grassland Sciences, ETH Zürich, Zurich, Switzerland; Valter Di Cecco, Majella Seed Bank, Majella National Park, Lama dei Peligni, Italy; Vanessa Rego, Postgraduate Program in Ecology and Biodiversity Conservation, Federal University of Mato Grosso, Cuiabá, Brazil; Veronika Fontana, Institute for Alpine Environment, Eurac
Research, Bozen, Italy; Veronika Piscová, Institute of Landscape Ecology of Slovak Academy of Sciences - Branch Nitra, Nitra, Slovakia; Vincent Bretagnolle, AGRIPOP, CEBC-CNRS \& LTSER ZAPVS, Villiers-en-Bois, France; Vincent Maire, Université du Québec à Trois-Rivières, Trois-Rivières, QC, Canada; Vinicius Farjalla, Departamento de Ecologia, Instituto de Biologia, Federal University of Rio de Janeiro, Rio de Janeiro, Brazil; Vittoz Pascal, Institute of Earth Surface Dynamics, Faculty of Geosciences and Environment, University of Lausanne, Lausanne, Switzerland; Wenjun Zhou, Xishuangbanna Tropical Botanical Garden, Chinese Academy of Sciences, Kunming, China; CAS Key Laboratory of Tropical Forest Ecology, Xishuangbanna Tropical Botanical Garden, Chinese Academy of Sciences, Mengla, China; Wentao Luo, Institute of Applied Ecology, Chinese Academy of Sciences, Shenyang, China; William Parker, Ontario Ministry of Natural Resources and Forestry, Peterborough, ON, Canada; Yasuhiro Utsumi, Ashoro Research Forest, Kyushu University, Hokkaido, Japan; Yuji Kominami, Forestry and Forest Products Research Institute (FFPRI), Kyoto, Japan; Zsolt Kotroczó, Department of Agro-Environmental Studies, Hungarian University of Agriculture and Life Sciences, Budapest, Hungary; Zsolt Tóth, Department of Soil Biology, Institute for Soil Sciences, Budapest, Hungary.

\section{DATA AVAILABILITY STATEMENT}

The original contributions presented in the study are included in the article/Supplementary Material, further inquiries can be directed to the corresponding author/s.

\section{AUTHOR CONTRIBUTIONS}

ID designed and coordinated the study with extensive input from CB. IS, SK-R, and KL accomplished data preparation. TK conducted statistical analyses and wrote the manuscript with contributions from all authors. The TeaComposition team implemented the study, provided site specific and climatic data, and contributed to manuscript editing.

\section{ACKNOWLEDGMENTS}

This work was performed within the TeaComposition initiative, carried out by 190 institutions worldwide. We thank for funding support for the workshop and data analysis from the ILTER. We acknowledge support by the German Centre for Integrative Biodiversity Research (iDiv) Halle-Jena-Leipzig, funded by the German Research Foundation (FZT 118), Scientific Grant Agency VEGA (Grant No. 2/0101/18), as well as by the European Research Council under the European Union's Horizon 2020 Research and Innovation Program (Grant Agreement No. 677232). Thanks are due to FCT/MCTES for the financial support to CESAM (UIDB/50017/2020 + UIDP/50017/2020) and to the project PORBIOTA (POCI-01-0145-FEDER-022127). AI Sousa was funded by national funds through the FCTFoundation for Science and Technology, I.P., under the project 
CEECIND/00962/2017. HS and CB acknowledge FCT support to cE3c through UID/BIA/00329/2013, UID/BIA/00329/2019, and UIDB/00329/2020, and the project PORBIOTA - POCI-010145-FEDER-022127. We are also thankful to UNILEVER for sponsoring the Lipton tea.

\section{REFERENCES}

Bates, D., Mächler, M., Bolker, B., and Walker, S. (2015). Fitting linear mixed-effects models using lme4. J. Stat. Softw. 67, 1-48. doi: 10.18637/jss.v067.i01

Berg, B. (2014). Decomposition patterns for foliar litter-a theory for influencing factors. Soil Biol. Biochem. 78, 222-232. doi: 10.1016/j.soilbio.2014.08.005

Berg, B., and McClaugherty, C. (2020). Plant litter: decomposition, humus formation, carbon sequestration. 4th edition. Berlin : Springer, doi: 10.1007/9783-030-59631-6

Bobbink, R., Hicks, K., Galloway, J., Spranger, T., Alkemade, R., Ashmore, M., et al. (2010). Global assessment of nitrogen deposition effects on terrestrial plant diversity: a synthesis. Ecol. App. 20, 30-59. doi: 10.1890/08-1140.1

Boutin, M., Corcket, E., Alard, D., Villar, L., Jiménez, J. J., Blaix, C., et al. (2017). Nitrogen deposition and climate change have increased vascular plant species richness and altered the composition of grazed subalpine grasslands. J. Ecol. 105, 1199-1209. doi: 10.1111/1365-2745.12743

Bowler, D. E., Bjorkman, A. D., Dornelas, M., Myers-Smith, I. H., Navarro, L. M., Niamir, A., et al. (2020). Mapping human pressures on biodiversity across the planet uncovers anthropogenic threat complexes. People Nat. 2, 380-394. doi: $10.1101 / 432880$

Bradford, M. A., Berg, B., Maynard, D. S., Wieder, W. R., and Wood, S. A. (2016). Understanding the dominant controls on litter decomposition. J. Ecol. 104, 229-238. doi: 10.1111/1365-2745.12507

Bringmark, E., Bringmark, L., Sonesten, L., Mjöfors, K., and Johansson, M. B. (2011). Long-term monitoring of scots pine litter decomposition rates throughout Sweden indicates formation of a more recalcitrant litter in the south. AMBIO 40, 878-890. doi: 10.1007/s13280-011-0202-0

Canessa, R., van den Brink, L., Saldaña, A., Rios, R. S., Hättenschwiler, S., Mueller, C. W., et al. (2021). Relative effects of climate and litter traits on decomposition change with time, climate and trait variability. J. Ecol. 109, 447-458. doi: 10. $1111 / 1365-2745.13516$

Carreiro, M. M., Sinsabaugh, R. L., Repert, D. A., and Parkhurst, D. F. (2000). Microbial enzyme shifts explain litter decay responses to simulated nitrogen deposition. Ecology 81, 2359-2365. doi: 10.1890/0012-96582000081

Chapin, F. S. III, Matson, P. A., and Vitousek, P. (2011). Principles of Terrestrial Ecosystem Ecology. Netherland: Springer, doi: 10.1007/978-1-4419-9504-9

Cornelissen, J. H. C., Van Bodegom, P. M., Aerts, R., Callaghan, T. V., Van Logtestijn, R. S. P., and Alatalo, J. (2007). Global negative vegetation feedback to climate warming responses of leaf litter decomposition rates in cold biomes. Ecol. Lett. 10, 619-627. doi: 10.1111/j.1461-0248.2007.01051.x

Cornell, S. E. (2011). Atmospheric nitrogen deposition: Revisiting the question of the importance of the organic component. Environ. Pollut. 159, 2214-2222. doi: 10.1016/j.envpol.2010.11.014

Cornwell, W. K., Cornelissen, J. H., Amatangelo, K., Dorrepaal, E., Eviner, V. T., Godoy, O., et al. (2008). Plant species traits are the predominant control on litter decomposition rates within biomes worldwide. Ecol. Lett. 11, 1065-1071. doi: 10.1111/j.1461-0248.2008.01219.x

Coûteaux, M. M., Bottner, P., and Berg, B. (1995). Litter decomposition, climate and litter quality. Trends Ecol. Evol. 10, 63-66. doi: 10.1016/S0169-5347(00) 88978-8

Crowther, T. W., Van den Hoogen, J., Wan, J., Mayes, M. A., Keiser, A. D., Mo, L., et al. (2019). The global soil community and its influence on biogeochemistry. Science 365:550. doi: 10.1126/science.aav0550

Currie, W. S., Harmon, M. E., Burke, I. C., Hart, S. C., Parton, W. J., and Silver, W. (2010). Cross-biome transplants of plant litter show decomposition models extend to a broader climatic range but lose predictability at the decadal time scale. Glob. Chang. Biol. 16, 1744-1761. doi: 10.1111/j.1365-2486.2009.02086.x

Davidson, E. A., and Janssens, I. A. (2006). Temperature sensitivity of soil carbon decomposition and feedbacks to climate change. Nature 440:165. doi: 10.1038/ nature04514

\section{SUPPLEMENTARY MATERIAL}

The Supplementary Material for this article can be found online at: https://www.frontiersin.org/articles/10.3389/ffgc.2021. 678480/full\#supplementary-material

De Mendiburu, F. (2017). Agricolae: Statistical Procedures for Agricultural Research. $R$ package version 1.2-6.

Delgado-Baquerizo, M., García-Palacios, P., Milla, R., Gallardo, A., and Maestre, F. T. (2015). Soil characteristics determine soil carbon and nitrogen availability during leaf litter decomposition regardless of litter quality. Soil Biol. Biochem. 81, 134-142. doi: 10.1016/j.soilbio.2014.11.009

Dirnböck, T., Djukic, I., Kitzler, B., Kobler, J., Mol-Dijkstra, J. P., Posch, M., et al. (2017). Climate and air pollution impacts on habitat suitability of Austrian forest ecosystems. PLoS One 12:e0184194. doi: 10.1371/journal.pone.0184194

Djukic, I., Kepfer-Rojas, S., Schmidt, I. K., Larsen, K. S., Beier, C., Berg, B., et al. (2018). Early stage litter decomposition across biomes. Sci. Total Environ. 628, 1369-1394. doi: 10.1016/j.scitotenv.2018.01.012

Fanin, N., Bezaud, S., Sarneel, J. M., Cecchini, S., Nicolas, M., and Augusto, L. (2020). Relative importance of climate, soil and plant functional traits during the early decomposition stage of standardized litter. Ecosystems 23, 1-15. doi: 10.1007/s10021-019-00452-Z

Fog, K. (1988). The effect of added nitrogen on the rate of decomposition of organic matter. Biol. Rev. 63, 433-462. doi: 10.1111/j.1469-185X.1988.tb00725.x

Forstner, S. J., Wechselberger, V., Müller, S., Keibinger, K. M., Díaz-Pinés, E., Wanek, W., et al. (2019). Vertical redistribution of soil organic carbon pools after twenty years of nitrogen addition in two temperate coniferous forests. Ecosystems 22, 379-400. doi: 10.1007/s10021-018-0275-8

Fröberg, M., Tipping, E., Stendahl, J., Clarke, N., and Bryant, C. (2011). Mean residence time of $\mathrm{O}$ horizon carbon along a climatic gradient in Scandinavia estimated by $14 \mathrm{C}$ measurements of archived soils. Biogeochemistry 104, $227-$ 236. doi: 10.1007/s10533-010-9497-3

Frøseth, R. B., and Bleken, M. A. (2015). Effect of low temperature and soil type on the decomposition rate of soil organic carbon and clover leaves, and related priming effect. Soil Biol. Biochem. 80, 156-166. doi: 10.1016/j.soilbio.2014.10. 004

Gaudio, N., Belyazid, S., Gendre, X., Mansat, A., Nicolas, M., Sverdrup, H., et al. (2015). Combined effect of atmospheric nitrogen deposition and climate change on temperate forest soil biogeochemistry: A modeling approach. Ecol. Modell. 306, 24-34. doi: 10.1016/j.ecolmodel.2014.10.002

González, G., and Seastedt, T. R. (2001). Soil fauna and plant litter decomposition in tropical and subalpine forests. Ecology 82, 955-964. doi: 10.2307/2 679895

Guerra, C. A., Bardgett, R. D., Caon, L., Crowther, T. W., Delgado-Baquerizo, M., Montanarella, L., et al. (2021). Tracking, targeting, and conserving soil biodiversity. Science 371, 239-241. doi: 10.1126/science.abd7926

Hagedorn, F., Kammer, A., Schmidt, M. W., and Goodale, C. L. (2012). Nitrogen addition alters mineralization dynamics of $13 \mathrm{C}$-depleted leaf and twig litter and reduces leaching of older DOC from mineral soil. Glob. Chang. Biol. 18, 1412-1427. doi: 10.1111/j.1365-2486.2011.02603.x

Hagedorn, F., and Machwitz, M. (2007). Controls on dissolved organic matter leaching from forest litter grown under elevated atmospheric $\mathrm{CO}_{2}$. Soil Biol. Biochem. 39, 1759-1769. doi: 10.1016/j.soilbio.2007.01.038

Henry, H. A., Cleland, E. E., Field, C. B., and Vitousek, P. M. (2005). Interactive effects of elevated $\mathrm{CO} 2, \mathrm{~N}$ deposition and climate change on plant litter quality in a California annual grassland. Oecologia 142, 465-473. doi: 10.1007/s00442004-1713-1

Hobbie, S. E. (2008). Nitrogen effects on decomposition: A five-year experiment in eight temperate sites. Ecology 89, 2633-2644. doi: 10.1890/07-1119.1

Hobbie, S. E., Eddy, W. C., Buyarski, C. R., Adair, E. C., Ogdahl, M. L., and Weisenhorn, P. (2012). Response of decomposing litter and its microbial community to multiple forms of nitrogen enrichment. Ecol. Monogr. 82, 389405. doi: 10.1890/11-1600.1

Hoffman, G. E., and Schadt, E. E. (2016). variancePartition: interpreting drivers of variation in complex gene expression studies. BMC Bioinform. 17:483. doi: $10.1186 / \mathrm{s} 12859-016-1323-\mathrm{z}$ 
Holm, S. (1979). A simple sequentially rejective multiple test procedure. Scand. J. Stat. 6, 65-70. doi: 10.2307/4615733

Hood-Nowotny, R., Schmittner, K., Ziss, E., Leitner, S., Watzinger, A., Gorfer, M., et al. (2021). Functional response of an Austrian forest soil to $\mathrm{N}$ addition. Environ. Res. Commun. 3:025001. doi: 10.1088/2515-7620/abe8c7

IPCC (2014). in Climate Change 2014: Synthesis Report. Contribution of Working Groups I, II and III to the Fifth Assessment Report of the Intergovernmental Panel on Climate Change, Geneva: IPCC, 151.

Janssens, I. A., Dieleman, W., Luyssaert, S., Subke, J. A., Reichstein, M., Ceulemans, R., et al. (2010). Reduction of forest soil respiration in response to nitrogen deposition. Nat. Geosci. 3, 315-322. doi: 10.1038/ngeo844

Juhos, K., Madarász, B., Kotroczó, Zs, Béni, Á, Makádi, M., and Fekete, I. (2021). Carbon sequestration of forest soils is reflected by changes in physicochemical soil indicators - A comprehensive discussion of a long-term experiment on a detritus manipulation. Geoderma 385:114918. doi: 10.1016/j.geoderma.2020. 114918

Kang, H., Berg, B., Liu, C., and Westman, C. J. (2009). Variation in Mass-Loss Rate of Foliar Litter in Relation to Climate and Litter Quality in Eurasian Forests: Differences among Functional Groups of Litter. Silva Fenn. 43, 549-575. doi: $10.14214 / \mathrm{sf} .180$

Karger, D. N., Conrad, O., Böhner, J., Kawohl, T., Kreft, H., Soria-Auza, R. W., et al. (2017). Climatologies at high resolution for the earth's land surface areas. Sci. Data 4:170122. doi: 10.1038/sdata.2017.122

Keuskamp, J. A., Dingemans, B. J., Lehtinen, T., Sarneel, J. M., and Hefting, M. M. (2013). Tea Bag Index: a novel approach to collect uniform decomposition data across ecosystems. Methods Ecol. Evol. 4, 1070-1075. doi: 10.1111/2041-210X. 12097

Knorr, M., Frey, S. D., and Curtis, P. S. (2005). Nitrogen additions and litter decomposition: A meta-analysis. Ecology 86, 3252-3257. doi: 10.1890/05-0150

Kock, N., and Lynn, G. (2012). Lateral collinearity and misleading results in variance-based SEM: An illustration and recommendations. J. Assoc. Inf. Syst. 13, 546-580. doi: 10.17705/1jais.00302

Kotroczó, Z. S., Juhos, K., Biró, B., Kocsis, T., Pabar, S. A., Varga, C. S., et al. (2020). Effect of Detritus Manipulation on Different Organic Matter Decompositions in Temperate Deciduous Forest Soils. Forests 11:675. doi: 10. 3390/f11060675

Lamarque, J. F., Dentener, F., McConnell, J., Ro, C. U., Shaw, M., Vet, R., et al. (2013). Multi-model mean nitrogen and sulfur deposition from the atmospheric chemistry and climate model intercomparison project (ACCMIP): evaluation of historical and projected future. Atmos. Chem. Phys. 13, 7997-8018. doi: 10.5194/acp-13-7997-2013

Leff, J. W., Jones, S. E., Prober, S. M., Barberán, A., Borer, E. T., Firn, J. L., et al. (2015). Consistent responses of soil microbial communities to elevated nutrient inputs in grasslands across the globe. Proc. Natl. Acad. Sci. U.S.A. 112, 10967-10972. doi: 10.1073/pnas.1508382112

Lilleskov, E. A., Kuyper, T. W., Bidartondo, M. I., and Hobbie, E. A. (2019). Atmospheric nitrogen deposition impacts on the structure and function of forest mycorrhizal communities: a review. Environ. Pollut. 246, 148-162. doi: 10.1016/j.envpol.2018.11.074

Luo, Y., Chen, H. Y., and Ruan, H. (2018). Responses of litter decomposition and nutrient release to $\mathrm{N}$ addition: A meta-analysis of terrestrial ecosystems. Agric. Ecosyst. Environ. Appl. Soil Ecol. 128, 35-42. doi: 10.1007/s11368-02002810-0

Makkonen, M., Berg, M. P., Handa, I. T., Hättenschwiler, S., van Ruijven, J., van Bodegom, P. M., et al. (2012). Highly consistent effects of plant litter identity and functional traits on decomposition across a latitudinal gradient. Ecol. Lett. 15, 1033-1041. doi: 10.1111/j.1461-0248.2012. 01826.x

Mori, T., Hashimoto, T., and Sakai, Y. (2021). Evaluating the tea bag method as a potential tool for detecting the effects of added nutrients and their interactions with climate on litter decomposition. bioRxiv [preprint] doi: 10.1101/2021.01. 28.428520

Mori, T., Sakai, Y., Aoyagi, R., and Taga, H. (2020). Effects of water content and mesh size on tea bag decomposition. bioRxiv [preprint] doi: 10.1101/2020.11. 15.384016

Mulder, C., Hettelingh, J. P., Montanarella, L., Pasimeni, M. R., Posch, M., Voigt, W., et al. (2015). Chemical footprints of anthropogenic nitrogen deposition on recent soil C: N ratios in Europe. Biogeosciences 12, 4113-4119. doi: 10.5194/ bg-12-4113-2015

Nakagawa, S., and Schielzeth, H. (2013). A general and simple method for obtaining R2 from generalized linear mixed-effects models. Methods Ecol. Evol. 4, 133-142. doi: 10.1111/J.2041-210x.2012.00261.X

Neff, J. C., Holland, E. A., Dentener, F. J., McDowell, W. H., and Russell, K. M. (2002). The origin, composition and rates of organic nitrogen deposition: a missing piece of the nitrogen cycle? Biogeochemistry 57, 99-136. doi: 10.1023/A: 1015791622742

Norris, M. D., Avis, P. G., Reich, P. B., and Hobbie, S. E. (2013). Positive feedbacks between decomposition and soil nitrogen availability along fertility gradients. Plant Soil 367, 347-361. doi: 10.1007/s11104-012-1449-3

Parton, W., Silver, W. L., Burke, I. C., Grassens, L., Harmon, M. E., Currie, W. S., et al. (2007). Global-scale similarities in nitrogen release patterns during longterm decomposition. Science 315, 361-364. doi: 10.1126/science.1134853

Pei, G., Liu, J., Peng, B., Wang, C., Jiang, P., and Bai, E. (2020). Nonlinear Coupling of Carbon and Nitrogen Release During Litter Decomposition and its Responses to Nitrogen Addition. J. Geophys. Res. Biogeosci. 125:5462. doi: 10.1029/2019JG005462

Pioli, S., Sarneel, J., Thomas, H. J. D., Domene, X., Andres, P., Hefting, M., et al. (2020). Linking plant litter microbial diversity to microhabitat conditions, environmental gradients and litter mass loss: Insights from a European study using standard litterbags. Soil Biol. Biochem. 144:107778. doi: 10.1016/j.soilbio. 2020.107778

Prescott, C. E. (2005). Do rates of litter decomposition tell us anything we really need to know? For. Ecol. Manag. 220, 66-74. doi: 10.1016/j.foreco.2005. 08.005

Prescott, C. E. (2010). Litter decomposition: what controls it and how can we alter it to sequester more carbon in forest soils? Biogeochemistry 101, 133-149. doi: 10.1007/s10533-010-9439-0

Quantum GIS Development Team (2017). Quantum GIS Geographic Information System. Open Source Geospatial Foundation Project. Version 2.18.14. Germany: Quantum GIS Development Team.

R Core Team (2019). R: A Language and Environment for Statistical Computing. Vienna: R Foundation for Statistical Computing.

Rillig, M. C., Ryo, M., Lehmann, A., Aguilar-Trigueros, C. A., Buchert, S., Wulf, A., et al. (2019). The role of multiple global change factors in driving soil functions and microbial biodiversity. Science 366, 886-890. doi: 10.1126/ science.aay 2832

Ristok, C., Leppert, K. N., Franke, K., Scherer-Lorenzen, M., Niklaus, P. A., Wessjohann, L. A., et al. (2017). Leaf litter diversity positively affects the decomposition of plant polyphenols. Plant Soil 419, 305-317. doi: 10.1007/ s11104-017-3340-8

Rizzetto, S., Belyazid, S., Gégout, J. C., Nicolas, M., Alard, D., Corcket, E., et al. (2016). Modelling the impact of climate change and atmospheric $\mathrm{N}$ deposition on French forests biodiversity. Environ. Pollut. 213, 1016-1027. doi: 10.1016/j. envpol.2015.12.048

See, C. R., Luke McCormack, M., Hobbie, S. E., Flores-Moreno, H., Silver, W. L., and Kennedy, P. G. (2019). Global patterns in fine root decomposition: climate, chemistry, mycorrhizal association and woodiness. Ecol. Lett. 22, 946-953. doi: 10.1111/ele.13248

Thorpe, L., and Andrews, T. (2014). The physical drivers of historical and 21st century global precipitation changes. Environ. Res. Lett. 9:064024. doi: 10.1088/ $1748-9326 / 9 / 6 / 064024$

Tóth, J. A., Lajtha, K., Kotroczó, Z. S., Krakomperger, Z. S., Caldwel, B., Bowden, R. D., et al. (2007). The effect of climate change on soil organic matter decomposition. Acta Silv. Lign. Hung. 3, 75-85.

Trevathan-Tackett, S. M., Brodersen, K. E., and Macreadie, P. I. (2020). Effects of elevated temperature on microbial breakdown of seagrass leaf and tea litter biomass. Biogeochemistry 151, 171-185. doi: 10.1007/s10533-02000715-1

Van Vuuren, D. P., Edmonds, J., Kainuma, M., Riahi, K., Thomson, A., Hibbard, K., et al. (2011). The representative concentration pathways: an overview. Clim. Change 109, 5-31. doi: 10.1007/s10584-011-0148-z

Virkkala, A. M., Abdi, A. M., Luoto, M., and Metcalfe, D. B. (2019). Identifying multidisciplinary research gaps across Arctic terrestrial gradients. Environ. Res. Lett. 14:124061. doi: 10.1088/1748-9326/ab4291 
Walter, H., and Breckle, S. W. (1999). Vegetation und Klimazonen. 544. Ulmer: Stuttgart.

Wang, B., Blondeel, H., Baeten, L., Djukic, I., De Lombaerde, E., and Verheyen, K. (2019). Direct and understorey-mediated indirect effects of human-induced environmental changes on litter decomposition in temperate forest. Soil Biol. Biochem. 138:107579. doi: 10.1016/j.soilbio.2019.107579

Zhang, D., Hui, D., Luo, Y., and Zhou, G. (2008). Rates of litter decomposition in terrestrial ecosystems: global patterns and controlling factors. J. Plant Ecol. 1, 85-93. doi: 10.1093/jpe/rtn002

Zhou, Z., Wang, C., Zheng, M., Jiang, L., and Luo, Y. (2017). Patterns and mechanisms of responses by soil microbial communities to nitrogen addition. Soil Biol. Biochem. 115, 433-441. doi: 10.1016/j.soilbio.2017.09.015
Conflict of Interest: The authors declare that the research was conducted in the absence of any commercial or financial relationships that could be construed as a potential conflict of interest.

Copyright () 2021 Kwon, Shibata, Kepfer-Rojas, Schmidt, Larsen, Beier, Berg, Verheyen, Lamarque, Hagedorn, Eisenhauer, Djukic and TeaComposition Network. This is an open-access article distributed under the terms of the Creative Commons Attribution License (CC BY). The use, distribution or reproduction in other forums is permitted, provided the original author(s) and the copyright owner(s) are credited and that the original publication in this journal is cited, in accordance with accepted academic practice. No use, distribution or reproduction is permitted which does not comply with these terms. 